Article

\title{
Analysis and Assessment of BDS-2 and BDS-3 Broadcast Ephemeris: Accuracy, the Datum of Broadcast Clocks and Its Impact on Single Point Positioning
}

\author{
Guoqiang Jiao ${ }^{1,2} \mathbb{D}$, Shuli Song ${ }^{1, *}$, Yangyang Liu ${ }^{3}$, Ke Su ${ }^{1,2} \mathbb{D}$, Na Cheng ${ }^{4}$ and Shengli Wang 5 \\ 1 Shanghai Astronomical Observatory, Chinese Academy of Sciences, Shanghai 200030, China; \\ jiaoguoqiang@shao.ac.cn (G.J.); ksu@shao.ac.cn (K.S.) \\ 2 School of Astronomy and Space Science, University of Chinese Academy of Sciences, Beijing 100049, China \\ 3 National Time Service Center, Chinese Academy of Sciences, Xi'an 710600, China; liuyangyang@ntsc.ac.cn \\ 4 College of Surveying And Geo-Informatics, Shandong Jianzhu University, Jinan 250101, China; \\ chengna19@sdjzu.edu.cn \\ 5 College of Ocean Science and Engineering, Shandong University of Science and Technology, \\ Qingdao 266590, China; shlwang@sdust.edu.cn \\ * Correspondence: slsong@shao.ac.cn
}

Received: 22 May 2020; Accepted: 27 June 2020; Published: 29 June 2020

\begin{abstract}
For the global ordinary users, the broadcast ephemeris plays important roles in positioning, navigation and timing (PNT) services. With the construction of a new generation of the BeiDou navigation satellite system (BDS), the development of BDS has entered the era of globalization. It is meaningful for global users to analyze and assess the BDS-2 and BDS-3 broadcast ephemeris. Therefore, the satellite orbits and clock offsets calculated by broadcast ephemeris are compared with the precise orbit and clock offset products provided by three analysis centers (i.e., Helmholtz Centre Potsdam German Research Center for Geosciences (GFZ), Wuhan University (WHU) and Shanghai Astronomical Observatory (SHA)), and the corresponding signal-in-space range error (SISRE) and the orbit-only SISRE are analyzed to assess the accuracy of BDS broadcast ephemeris. Due to the upgrade of BDS-3 satellite hardware technology and inter-satellite links payload and the development of satellite orbit determination algorithm, the accuracy of broadcast orbit and clock offsets has been greatly improved. The root mean square (RMS) of BDS-3 broadcast orbit errors is improved by $86.30 \%$, $89.47 \%$ and $76.86 \%$, and the standard deviation (STD) is improved by $79.41 \%, 77.00 \%$ and $76.78 \%$ compared with BDS-2 in the radial, along-track and cross-track directions. The corresponding RMS and STD of all BDS-3 satellite clock offsets are improved by $40.34 \%$ and $52.49 \%$ than that of BDS-2, respectively. Meanwhile, the mean RMS and STD are $1.78 \mathrm{~m}$ and $0.40 \mathrm{~m}$ for BDS-2 SISRE, $1.72 \mathrm{~m}$ and $0.34 \mathrm{~m}$ for BDS-2 orbit-only SISRE, $0.50 \mathrm{~m}$ and $0.14 \mathrm{~m}$ for BDS-3 SISRE, and $0.17 \mathrm{~m}$ and $0.04 \mathrm{~m}$ for BDS-3 orbit-only SISRE. It is noteworthy that the average broadcast-minus-precise (BMP) clock values of BDS-2 and BDS-3 are inconsistent, which can indirectly prove that the datum of broadcast clock offsets for BDS-2 and BDS-3 are inconsistent. The inconsistency of the datum of satellite clock offsets and receiver hardware delay bias between BDS-2 and BDS-3 will result in the inter-system bias (ISB) on the receiver segment. For JAVAD TRE_3 receivers, the ISB is relatively small and thus can be ignored. However, for the TRIMBLE ALLOY, SEPT POLARX5, CETC-54-GMR-4016, CETC-54-GMR-4011, GNSS-GGR and UB4B0-13478 receivers, estimating ISB can improve the positioning accuracy of single point positioning (SPP) by $20.15 \%, 19.81 \%$ and $12.76 \%$ in north, east and up directions, respectively.
\end{abstract}

Keywords: BDS-3; the datum of broadcast clocks; inter-system bias (ISB); signal-in-space ranging error (SISRE); single point positioning (SPP) 


\section{Introduction}

The BeiDou navigation satellite system (BDS) independently developed by China follows three construction phases, including the demonstration system (BDS-1) consisting of three Geostationary Earth Orbit (GEO) satellites, the regional system (BDS-2) composed of five GEO satellites, seven Inclined Geosynchronous Satellite Orbit (IGSO) satellites and three Medium Earth Orbit (MEO) satellites, and the global system (BDS-3) containing three GEO, three IGSO and 24 MEO satellites [1-4]. With the centralized launch of BDS-3 satellites, all BDS-3 MEO satellites were launched on or before December 16, 2019, and the core constellation deployment of the BDS-3 global system has been completed. The performance of global positioning, navigation and timing (PNT) services will be further improved.

With the gradual deployment of the BDS-3 constellation, the BDS constellation will include the satellite systems of BDS-2 and BDS-3. So, the observations of BDS-2 and BDS-3 need to be fully used to take full advantage of the BDS potential. Therefore, it is meaningful for global BDS users to assess the accuracy of BDS-2 and BDS-3 broadcast ephemeris and compare their differences. About the analysis and assessment of BDS broadcast ephemeris, Montenbruck and Steigenberger assessed the GPS, BDS-2, GLONASS, Galileo and QZSS in terms of broadcast orbit errors, clock offsets errors and signal-in-space range error (SISRE), indicating that the SISRE values of BDS-2 are $1.5 \mathrm{~m}$ with a monthly scatter of $0.1 \mathrm{~m}$, which is better than GLONASS and the (nonoperational) Galileo IOV system [5]. The initial assessment of BDS-3 broadcast ephemeris in terms of BDS-3 orbit, clock offsets, SISRE and orbit-only SISRE is presented by Lv and Geng, concluding that the 3D orbit errors are better than $0.6 \mathrm{~m}$, and the root mean square (RMS) of SISRE and orbit-only SISRE are $0.5 \mathrm{~m}$ and $0.1 \mathrm{~m}$, respectively [6]. Zhang and Kubo used the precise product provided by the GNSS Research Center of Wuhan University (WHU) to evaluate the BDS-2 and BDS-3, which shows that the BDS-3 SISRE is superior to that of BDS-2, and the corresponding values are $0.71 \mathrm{~m}$ and $0.97 \mathrm{~m}$, respectively [7].

For the assessment of BDS signal-in-space accuracy, especially for BDS-3, most researchers only use the precise orbit and clock offsets provided by WHU to assess the accuracy of BDS-3 broadcast ephemeris. The RMS of orbit errors and the accuracy of clock offsets and SISRE (including the orbit-only SISRE) used to evaluate the accuracy of BDS broadcast ephemeris will inevitably be affected by the accuracy and the datum of precise product. The conclusions drawn by using the precise satellite product obtained from one analysis center (AC) lack slight reliability. Hence, the precise products provided by the Helmholtz Centre Potsdam German Research Center for Geosciences (GFZ), Wuhan University (WHU) and the International GNSS Monitoring and Assessment System (iGMAS) ACs of Shanghai Astronomical Observatory (SHA) are used to assess the BDS signal-in-space accuracy to draw more scientific and reliable conclusions.

In fact, the broadcast ephemeris of BDS-2 and BDS-3 are calculated separately. Although the corrections of unifying the datum of BDS-2 and BDS-3 satellite clock offsets are considered in the BDS information processing, an obvious systematic bias between BDS-2 and BDS-3 is found by comparing the broadcast ephemeris and precise products in terms of satellite orbit and clock offsets. The previous research indicated that there is a pseudorange bias (hardware delay bias) between BDS-2 and BDS-3 in some receivers [8]. The pseudorange bias of the receiver will still produce the inconsistency of the datum of clock offsets for BDS-2 and BDS-3 during the processing of broadcast clock offsets. Most references ignore the inconsistency of the datum of satellite clock offsets in evaluating the accuracy of BDS broadcast ephemeris and positioning [7,9]. Only Wang and Li found a datum deviation of $3.8 \mathrm{~ns}$ between BDS-2 and BDS-3 by comparing the differential code bias (DCB) and time group delay (TGD) of BDS-3 satellites [10]. Zhang and Wang further attributed this inconsistency to satellite-dependent TGD bias of the BDS broadcast ephemeris, and corrected this inconsistency by calculating TGD bias [11,12]. Although the corrections of TGD bias can weaken the impact of the inconsistency of the datum of satellite clock offsets on the assessment of BDS-2 and BDS-3 signal-in-space accuracy, the inter-system bias (ISB) between BDS-2 and BDS-3 is affected by both the datum of satellite clock offsets and receiver pseudorange bias [13-16]. The receiver pseudorange bias and residuals of these corrections affected by the number of tracking stations and the accuracy of satellite orbits and ionospheric products 
will continue to affect the assessment of BDS-2 and BDS-3 signal-in-space accuracy and single point positioning (SPP).

With this background, we give the evaluation methods of broadcast clock offsets and SISRE and the new BDS-2 and BDS-3 combined SPP model in Section 2. The datasets needed for the assessment of BDS broadcast ephemeris and the SPP processing strategy are presented in Section 3. In Section 4, we first analyze the accuracy of broadcast orbit and clock offsets, SISRE and orbit-only SISRE, and prove that the datum of broadcast clock offsets for BDS-2 and BDS-3 are inconsistent by comparing average broadcast-minus-precise (BMP) clock values of BDS-2 and BDS-3 during the assessment of broadcast clock offsets. Then, we investigate the impact of the inconsistent datum of broadcast clock offsets on BDS-2 and BDS-3 combined SPP. Finally, some conclusions and recommendations are drawn.

\section{Methods}

To analyze and assess the BDS-2 and BDS- 3 broadcast ephemeris, we begin with the evaluation and calculation methods of broadcast ephemeris and the SISRE. For BDS broadcast orbits, BDS interface control document (ICD) gives the calculation methods, which will not be discussed in this contribution [17-19]. As for the evaluation and calculation methods of satellite clock offsets, a deep analysis in detail is offered in this section. Finally, the traditional BDS SPP and new BDS-2 and BDS-3 combined SPP models considering ISB are developed in this section.

\subsection{BDS Satellite Clock Offsets}

The precise satellite clocks products are generated by the ionospheric-free (IF) observation model, the precise clock offsets will absorb the satellite IF uncalibrated code delays (UCDs) [20,21]. It is noteworthy that the BDS broadcast clock offsets are determined by Two-way Satellite Time Frequency Transfer (TWSTFT) [22,23], and the equipment group delay of BDS B3I $(1268.520 \mathrm{MHz})$ is treated as the reference equipment group delay. Whether BDS-2 or BDS-3, the equipment group delay of B3I will be absorbed by the satellite broadcast clock offsets. The broadcast clock offsets and precise clock offsets can be expressed as [22,24]:

$$
\left\{\begin{array}{l}
\delta \mathrm{t}_{\text {Broadcast }}^{\mathrm{S}}=\delta \mathrm{t}^{\mathrm{S}}+\mathrm{B}_{\mathrm{B} 3 \mathrm{I}}+\mathrm{dD}_{\text {Broadcast }} \\
\delta \mathrm{T}_{\text {Precise }}^{\mathrm{S}}=\delta \mathrm{T}^{\mathrm{S}}+\mathrm{IF}_{\mathrm{UCD}}+\mathrm{dD}_{\text {Precise }}
\end{array}\right.
$$

where $\delta t_{\text {Broadcast }}^{S}$ and $\delta T_{\text {Precise }}^{S}$ represent broadcast and precise clock offsets calculated by the recommendation model of BDS ICD and International GNSS Service (IGS) product descriptions [17-19,25]; $\mathrm{B}_{\mathrm{B} 3 \mathrm{I}}$ is the equipment group delay of $\mathrm{B} 3 \mathrm{I}$. $\mathrm{IF}_{\mathrm{UCD}}$ is the satellite IF UCDs. $\mathrm{dD}_{\text {Broadcast }}$ and $\mathrm{dD}$ Precise denote the receiver-independent bias introduced through broadcast and precise satellite clock estimation. As mentioned above, the BDS original broadcast clock offsets are determined by TWSTFT, not IF observation model [22,23]. Therefore, $\mathrm{dD}_{\text {Broadcast }}$ will absorb the datum of TGD when TGD correction is performed to convert the original clock offsets to the clock offsets with a certain equipment group delay. Previous studies have shown that the TGD of BDS-2 and BDS-3 are also calculated by two information processing centers [12] and the inconsistency of the TGD datum for BDS-2 and BDS-3 resulted from different solution conditions will cause the inconsistency of the datum of satellite clock offsets between BDS-2 and BDS-3.

After TGD correction, the broadcast clock offsets absorbed the equipment group delay of B3I can be restored to the clock offsets absorbed the equipment group delay of IF combination between B1I $(1561.098 \mathrm{MHz})$ and B3I (1268.520 MHz):

$$
\delta \mathrm{t}_{\mathrm{IF}, \text { Broadcast }}^{\mathrm{S}}=\delta \mathrm{t}^{\mathrm{S}}+\mathrm{IF}_{\mathrm{BP}_{\mathrm{P}}}+\mathrm{dD}_{\text {Broadcast }}=\delta \mathrm{t}_{\text {Broadcast }}^{\mathrm{S}}+\frac{\mathrm{f}_{\mathrm{B} 1 \mathrm{I}}^{2}}{\mathrm{f}_{\mathrm{B} 1 \mathrm{I}}^{2}-\mathrm{f}_{\mathrm{B} 3 \mathrm{I}}^{2}} \cdot \mathrm{TGD}_{1}
$$


where $\delta \mathrm{t}_{\mathrm{IF}}^{\mathrm{S} \text {, Broadcast }}$ is the broadcast clock offsets absorbing the IF equipment group delay $\mathrm{IF}_{\mathrm{B}} ; \mathrm{f}_{\mathrm{B} 1 \mathrm{I}}$ and $\mathrm{f}_{\mathrm{B} 3 \mathrm{I}}$ are the frequencies on the B1I and B3I signals, respectively; $\mathrm{TGD}_{1}$ is the differential equipment group delay between the B1I and B3I.

In order to get the accuracy of broadcast clock offsets, we make a difference between broadcast clock offsets and precise clock offsets, which can be expressed as:

$$
\Delta \mathrm{t}=\delta \mathrm{t}_{\mathrm{IF}, \text { Broadcast }}^{\mathrm{S}}-\delta \mathrm{T}_{\text {Precise }}^{\mathrm{S}}=\left(\left(\delta \mathrm{t}^{\mathrm{S}}+\mathrm{IF}_{\mathrm{B}_{\mathrm{P}}}\right)-\left(\delta \mathrm{T}^{\mathrm{S}}+\mathrm{IF}_{\mathrm{UCDs}}\right)\right)+\mathrm{dD}_{\text {Broadcast }}-\mathrm{dD}_{\text {precise }}
$$

where $\Delta \mathrm{t}$ is the BMP clock value.

As shown in Equation (3), the datum of the satellite clock offsets cannot be eliminated by the first-order difference, so we need the double difference to eliminate the datum. The error of the broadcast clock offset $\nabla \Delta \mathrm{t}$ can be computed by subtracting the average of all satellite in a constellation from BMP clock values of each satellite at each epoch [5]:

$$
\begin{aligned}
& \nabla \Delta \mathrm{t}=\Delta \mathrm{t}-\mathrm{Ave}_{\mathrm{CLK}} \\
& \text { Ave }_{C L K}=\frac{\sum_{\mathrm{i}}^{\mathrm{n}} \Delta \mathrm{t}_{\mathrm{i}}}{\mathrm{n}}=\frac{\sum_{\mathrm{i}}^{\mathrm{n}}\left(\left(\delta \mathrm{t}^{\mathrm{i}}+\mathrm{IF}_{\mathrm{B}_{\mathrm{P}}}^{\mathrm{i}}\right)-\left(\delta \mathrm{T}^{\mathrm{i}}+\mathrm{IF}_{\mathrm{UCDs}}^{\mathrm{i}}\right)\right)}{\mathrm{n}}+\mathrm{dD}_{\text {Broadcast }}-\mathrm{dD}_{\text {precise }}
\end{aligned}
$$

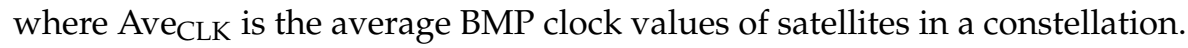

\subsection{Signal-in-Space Range Error}

The SISRE was developed in detail to assess the accuracy of the broadcast ephemeris, and the solution method is shown in Figure 1.

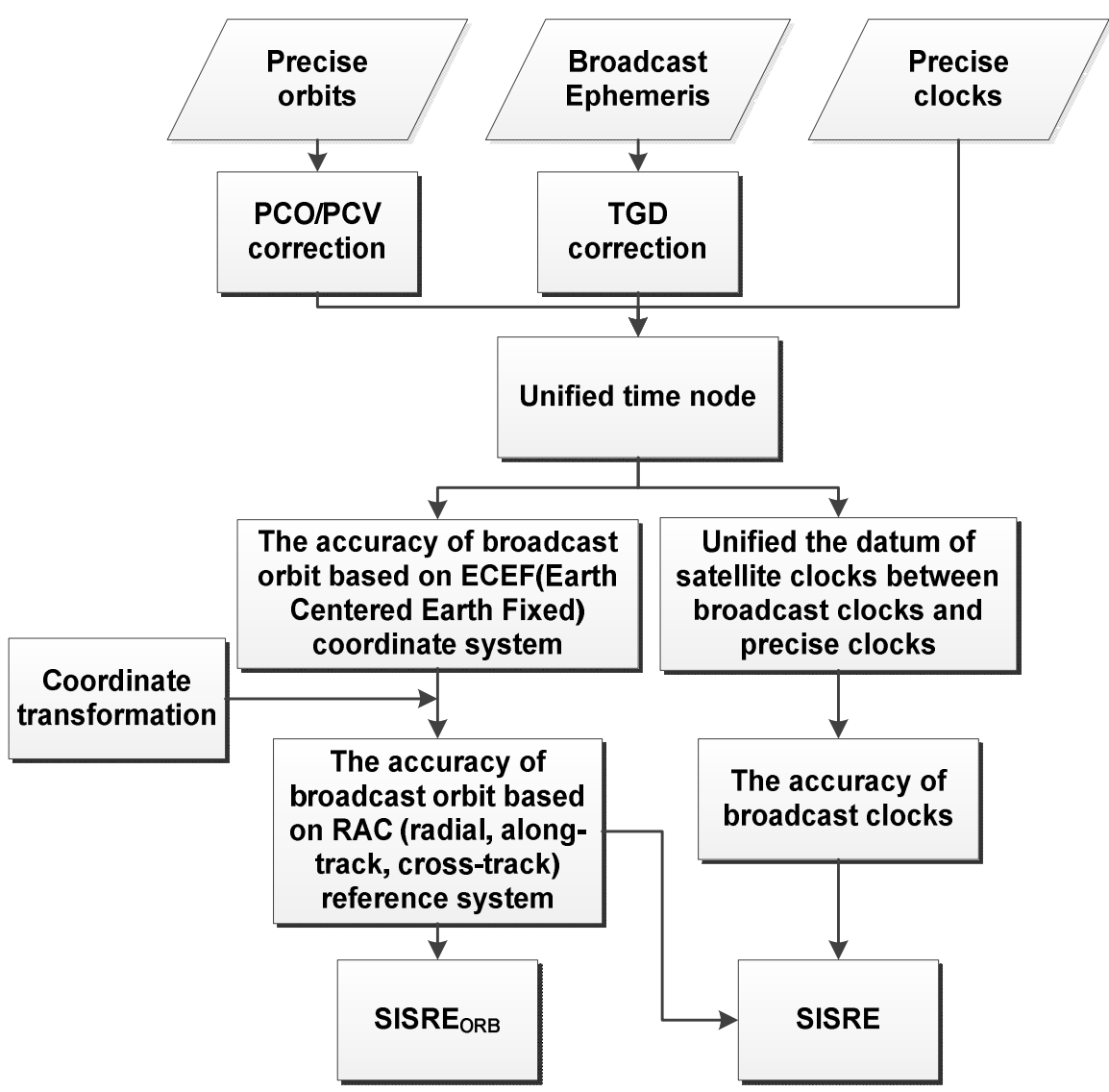

Figure 1. The flow chart for assessment of Broadcast orbit and clock accuracy and calculation of signal-in-space range error (SISRE). 
According to Montenbruck and Steigenberger [5,26], the orbit-only SISRE can be expressed as:

$$
\operatorname{SISRE}_{\mathrm{ORB}}=\sqrt{\mathrm{w}_{\mathrm{R}}^{2} \cdot \mathrm{R}^{2}+\mathrm{w}_{\mathrm{A}, \mathrm{C}}^{2} \cdot\left(\mathrm{A}^{2}+\mathrm{C}^{2}\right)}
$$

where SISRE $\mathrm{ORB}_{\text {is }}$ is the orbit-only SISRE; $\mathrm{W}_{\mathrm{R}}$ and $\mathrm{W}_{\mathrm{A}, \mathrm{C}}^{2}$ are the weight factor of orbit errors for radial as well as along-track and cross-track. $W_{\mathrm{R}}$ and $\mathrm{W}_{\mathrm{A}, \mathrm{C}}^{2}$ are 0.98 and 1/54 for BDS MEO satellites, 0.99 and 1/126 for BDS GEO and IGSO satellites [5].

Simultaneously, considering the contribution of the accuracy of clock offsets to SISRE, the equation can be expressed as:

$$
\text { SISRE }=\sqrt{\left(w_{R} \cdot R-c \cdot \nabla \Delta t\right)^{2}+w_{A, C}^{2} \cdot\left(A^{2}+C^{2}\right)}
$$

The only difference from Equation (6) is that the accuracy of clock offsets $\nabla \Delta t$ is considered.

\subsection{BDS Ionospheric-Free SPP Model}

The IF pseudorange observation model can be expressed as [9,27]:

$$
\mathrm{P}_{\mathrm{r}, \mathrm{IF}}^{\mathrm{S}}=\mathrm{u}_{\mathrm{r}}^{\mathrm{S}} \cdot \mathrm{x}+\mathrm{c} \cdot\left(\delta \mathrm{t}_{\mathrm{r}}-\delta \mathrm{t}^{\mathrm{S}}\right)+\mathrm{T}_{\text {trop }}+\mathrm{c} \cdot\left(\mathrm{IF}_{\mathrm{b}_{\mathrm{P}}}-\mathrm{IF}_{\mathrm{B}_{\mathrm{P}}}\right)+\varepsilon_{\mathrm{r}, \mathrm{IF}}^{\mathrm{S}}
$$

where $\mathrm{P}_{\mathrm{r}, \mathrm{IF}}^{\mathrm{S}}$ denotes the IF pseudorange observation; $\mathrm{u}_{\mathrm{r}}^{\mathrm{S}}$ is the unit vector form receiver $\mathrm{r}$ to satellite s; $x$ refers to the vector of the receiver position increments in three-dimensional (3D) directions; $\delta t_{r}$ and $\delta t^{S}$ are receiver and satellite clock offsets, respectively. $T_{\text {trop }}$ denotes tropospheric delay; $\mathrm{IF}_{\mathrm{b}_{\mathrm{P}}}$ and $\mathrm{IF}_{\mathrm{B}_{\mathrm{P}}}$ denote the receiver and satellite IF UCDs, respectively. $\varepsilon_{r, I F}^{\mathrm{S}}$ is the IF pseudorange observation noises containing multipath and higher-order ionospheric delay.

Combing Equations (1), (2) and (8), the BDS IF SPP model can be expressed as:

$$
\mathrm{P}_{\mathrm{r}, \mathrm{IF}}^{\mathrm{S}}=\mathrm{u}_{\mathrm{r}}^{\mathrm{S}} \cdot \mathrm{x}+\mathrm{c} \cdot\left(\delta \mathrm{t}_{\mathrm{r}}+\mathrm{IF}_{\mathrm{b}_{\mathrm{P}}}+\mathrm{dD}\right)-\mathrm{c} \cdot \delta \mathrm{t}_{\mathrm{IF}}^{\mathrm{S}}+\mathrm{T}_{\text {trop }}+\varepsilon_{\mathrm{r}, \mathrm{IF}}^{\mathrm{S}}
$$

Now turn to BDS-2 and BDS-3 combined SPP model, the receiver clock offsets of BDS-2 and BDS-3 absorb the receiver IF UCDs and the datum of satellite clock offsets of each system.

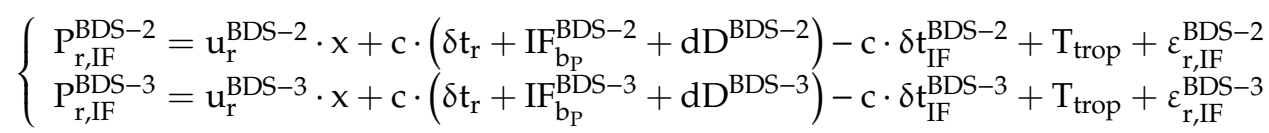

If no differences exist between BDS-2 and BDS-3 for the receiver IF UCDs and the datum of satellite clock offsets, the BDS-2 and BDS-3 combined IF SPP model can be expressed as:

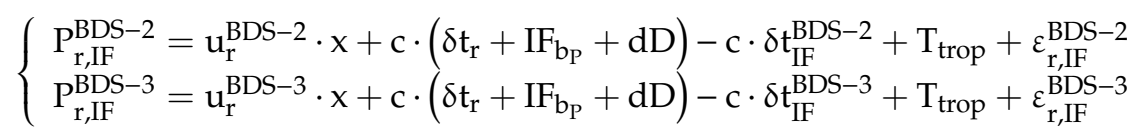

The estimated vector E1 in the IF SPP model includes receiver 3D position increments and the receiver clock offsets can be expressed as:

$$
\mathrm{E} 1=\left[\begin{array}{ll}
\mathrm{x} & \delta \mathrm{t}_{\mathrm{IF}}^{\mathrm{r}}
\end{array}\right]
$$

where $\delta t_{\mathrm{IF}}^{\mathrm{r}}=\delta \mathrm{t}_{\mathrm{r}}+\mathrm{IF}_{\mathrm{b}_{\mathrm{P}}}+\mathrm{dD}$.

If the differences exist between BDS-2 and BDS-3 in the receiver IF UCDs and the datum of satellite clock offsets, the BDS-2 and BDS-3 receiver clock offsets are inconsistent. The receiver clock offsets absorbed the BDS-2 receiver IF UCDs and the datum of BDS-2 satellite clock offsets are considered as the datum of the receiver's clock estimation. The BDS-2 and BDS-3 combined IF SPP model can be expressed as: 


$$
\left\{\begin{array}{ccc}
\mathrm{P}_{\mathrm{r}, \mathrm{IF}}^{\mathrm{BDS}-2}= & \mathrm{u}_{\mathrm{r}}^{\mathrm{BDS}-2} \cdot \mathrm{x}+\mathrm{c} \cdot\left(\delta \mathrm{t}_{\mathrm{r}}+\mathrm{IF}_{\mathrm{b}_{\mathrm{P}}}^{\mathrm{BDS}-2}+\mathrm{dD}^{\mathrm{BDS}-2}\right)-\mathrm{c} \cdot \delta \mathrm{t}^{\mathrm{BDS}-2}+\mathrm{T}_{\text {trop }}+\varepsilon_{\mathrm{r}, \mathrm{IF}}^{\mathrm{BDS}-2} \\
\mathrm{P}_{\mathrm{r}, \mathrm{IF}}^{\mathrm{BDS}-3}= & \mathrm{u}_{\mathrm{r}}^{\mathrm{BDS}-3} \cdot \mathrm{x}+\mathrm{c} \cdot\left(\delta \mathrm{t}_{\mathrm{r}}+\mathrm{IF}_{\mathrm{b}_{\mathrm{P}}}^{\mathrm{BDS}-2}+\mathrm{dD}^{\mathrm{BDS}-2}\right) \\
+ & \mathrm{c} \cdot\left(\mathrm{IF}_{\mathrm{b}_{\mathrm{P}}}^{\mathrm{BDS}-3}-\mathrm{IF}_{\mathrm{b}_{\mathrm{P}}}^{\mathrm{BDS}-2}+\mathrm{dD}^{\mathrm{BDS}-3}-\mathrm{dD}^{\mathrm{BDS}-2}\right)-\mathrm{c} \cdot \delta \mathrm{t}^{\mathrm{BDS}-3}+\mathrm{T}_{\text {trop }}+\varepsilon_{\mathrm{r}, \mathrm{IF}}^{\mathrm{BDS}-3}
\end{array}\right.
$$

In addition to the estimation parameters of E1, the estimated vector E2 also includes the ISB between BDS-2 and BDS-3, which can be expressed as:

$$
\mathrm{E} 2=\left[\begin{array}{lll}
\mathrm{x} & \delta \mathrm{t}_{\mathrm{IF}}^{\mathrm{r}, \mathrm{BDS}-2} & \mathrm{ISB}
\end{array}\right]
$$

where ISB $=\mathrm{IF}_{\mathrm{b}_{\mathrm{P}}}^{\mathrm{BDS}-3}-\mathrm{IF}_{\mathrm{b}_{\mathrm{P}}}^{\mathrm{BDS}-2}+\mathrm{dD}^{\mathrm{BDS}-3}-\mathrm{dD}^{\mathrm{BDS}-2}$. The ISB contains the receiver pseudorange bias and the inconsistency datum of satellite clock offsets between BDS-2 and BDS-3.

\section{Datasets and Processing Strategies}

To analyze and assess the BDS-2 and BDS-3 broadcast ephemeris in terms of the accuracy of broadcast orbit and clock offsets, the difference of the broadcast clock datum between BDS-2 and BDS-3 and its impact on BDS-2 and BDS-3 combined SPP, the BDS broadcast ephemeris (ftp: //ftp.pecny.cz/LDC/orbits_brd/gop3/) and precise orbit and clock offsets provided by the GFZ (ftp: //ftp.gfz-potsdam.de/GNSS/products/mgex/), WHU (ftp://igs.ign.fr/pub/igs/products/mgex/) and SHA (http://112.65.161.230/download/index.php) are used to calculate the accuracy of broadcast orbit and clock offsets, orbit-only SISRE and SISRE. Information on the precise products is listed in Table 1.

Table 1. The properties of BeiDou navigation satellite system (BDS) precise satellite orbit and clock offset products.

\begin{tabular}{ccccc}
\hline Agency & $\begin{array}{c}\text { Sampling Interval } \\
\text { of Orbit }\end{array}$ & $\begin{array}{c}\text { Sampling Interval } \\
\text { of Clock Offsets }\end{array}$ & Time System & Coordinate Frame \\
\hline GFZ & $5 \mathrm{~min}$ & $30 \mathrm{~s}$ & GPST & IGS14 \\
WHU & $15 \mathrm{~min}$ & $30 \mathrm{~s}$ & GPST & IGS14 \\
SHA & $15 \mathrm{~min}$ & $300 \mathrm{~s}$ & GPST & IGS14 \\
\hline
\end{tabular}

Due to the different solution strategies adopted by different ACs in terms of the precise attitude model, the solar radiation pressure model and the strategy of selecting the reference station during the estimation of precise clock offsets [28-32], the release of BDS-3 satellite precise products is also different. Figure 2 shows the missing of precise products obtained from GFZ, WHU and SHA.

The 10 IGS multi-GNSS experiment (MGEX) tracking stations [24] and 10 iGMAS tracking stations are selected to assess the BDS SPP performance and research the impact of the inconsistency datum of broadcast clock offsets and the receiver pseudorange bias on BDS-2 and BDS-3 combined SPP. Figure 3 shows the distribution of the selected stations. In order to descript the BDS service performances in these tracking stations, the corresponding mean position dilution of precision (PDOP) is marked in the geographical distribution. Incidentally, the global PDOP grid interval is $2.5^{\circ} \times 5^{\circ}$, and the cutoff elevation is set to $7.5^{\circ}$, which is consistent with SPP. All selected tracking stations can receive BDS-2 and BDS-3 observations, and the time interval is $30 \mathrm{~s}$. As with previous studies, the receiver type and the environmental factors (temperature and humidity, etc.) play important roles in the hardware delay [8,33-35]. Table 2 shows the properties of the selected stations.

These selected IGS MGEX and iGMAS tracking stations are used to perform SPP. The least-square method is applied in SPP, the antenna phase center offset (PCO) and phase center variations (PCVs) are corrected by using IGS ANTEX files [36,37]. About the tropospheric delay, the modified Hopfield model based on the Global Pressure and Temperature 3 (GPT3) model is used to correct the dry and wet tropospheric delay, and the mapping functions of both dry and wet parts are obtained by Vienna 
mapping functions 3 (VMF3) according to the elevation angle of each satellite [38]. The ISB processing strategies of not estimating ISB and estimating ISB are performed. Table 3 summarizes the processing strategies for BDS SPP.

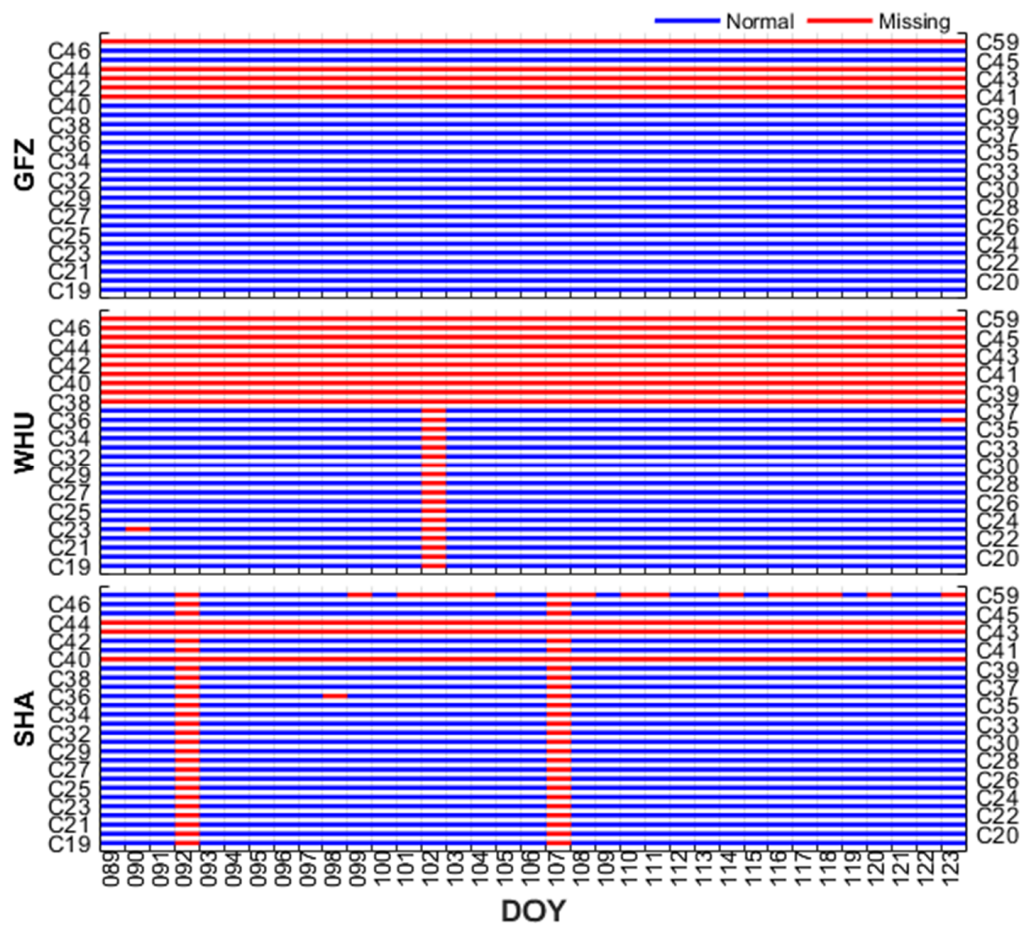

Figure 2. The missing of BDS-3 precise products obtained from the Helmholtz Centre Potsdam German Research Center for Geosciences (GFZ), Wuhan University (WHU) and Shanghai Astronomical Observatory (SHA) from DOY 089 to 123, 2020.

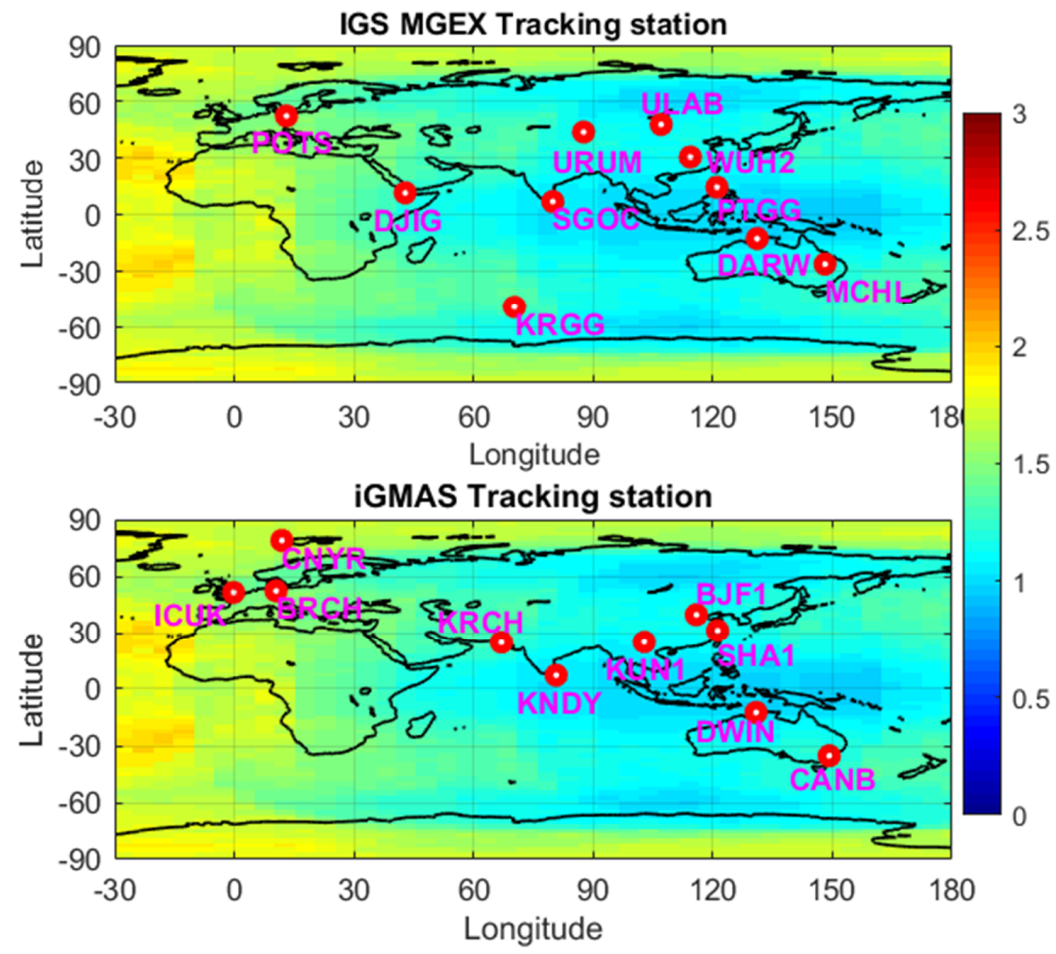

Figure 3. The geographical distribution of the selected stations and the mean position dilution of precision (PDOP) distributions of the corresponding area. 
Table 2. The properties of the selected stations included agency of tracking station, receiver type, manufacturer and antenna type.

\begin{tabular}{ccccc}
\hline Station & Agency & Receiver & Manufacturer & Antenna \\
\hline POTS & IGS MGEX & JAVAD TRE_3 & JAVAD & JAVRINGANT_G5T \\
SGOC & IGS MGEX & JAVAD TRE_3 & JAVAD & JAVRINGANT_G5T \\
ULAB & IGS MGEX & JAVAD TRE_3 & JAVAD & JAVRINGANT_G5T \\
URUM & IGS MGEX & JAVAD TRE_3 & JAVAD & JAVRINGANT_G5T \\
WUH2 & IGS MGEX & JAVAD TRE_3 & JAVAD & JAVRINGANT_G5T \\
KRGG & IGS MGEX & TRIMBLE ALLOY & TRIMBLE & LEIAR25.R4 \\
MCHL & IGS MGEX & TRIMBLE ALLOY & TRIMBLE & TRM59800.00 \\
KITG & IGS MGEX & SEPT POLARX5 & SEPTENTRO & JAVRINGANT_DM \\
DJIG & IGS MGEX & SEPT POLARX5 & SEPTENTRO & TRM59800.00 \\
PTGG & IGS MGEX & SEPT POLARX5 & SEPTENTRO & TRM59800.00 \\
BJF1 & iGMAS & CETC-54-GMR-4016 & CETC 54 & LEIAR25.R4 \\
BRCH & iGMAS & CETC-54-GMR-4016 & CETC 54 & NOV750.R4 \\
ICUK & iGMAS & CETC-54-GMR-4016 & CETC 54 & NovAtel-750 \\
KNDY & iGMAS & CETC-54-GMR-4016 & CETC 54 & GNSS-750 \\
CANB & iGMAS & CETC-54-GMR-4011 & CETC 54 & GNSS-750 \\
DWIN & iGMAS & CETC-54-GMR-4011 & CETC 54 & GNSS-750 \\
KRCH & iGMAS & UNICORE UB4B0I & UNICORE & NOV750.R4 \\
CNYR & iGMAS & UNICORE UB4B0I & UNICORE & NOV750.R4 \\
KUN1 & iGMAS & UB4B0-13478 & UNICORE & NOV750.R4 \\
SHA1 & iGMAS & UB4B0-13478 & UNICORE & NOV750.R4 \\
\hline
\end{tabular}

Table 3. Single point positioning (SPP) processing strategies.

\begin{tabular}{ll}
\hline \multicolumn{1}{c}{ Items } & Strategies \\
\hline Observations & Pseudorange observations \\
Frequency point & BDS-2: B1I/B3I; BDS-3: B1I/B3I \\
Elevation cutoff & $7.5^{\circ}[39,40]$ \\
Observation weighting & Elevation weight [sin(elevation)] \\
Satellite orbit & Fixed by broadcast ephemeris \\
Satellite clock offset & Fixed by broadcast ephemeris \\
Tropospheric delay & Modified Hopfield for dry and wet parts [41] \\
Ionospheric delay & IF linear combination \\
Receiver antenna & IGS values \\
Relativistic effect & Corrected [42] \\
Earth rotation & Fixed \\
Tide effect & Solid Earth, Pole and Ocean tide [42] \\
Receiver coordinate & Estimated \\
Receiver clock offset & Estimated \\
ISB & Strategy 1: No operation \\
Satellite TGD & Strategy 2: Estimated \\
\hline
\end{tabular}

\section{Result and Analysis}

\subsection{BDS-2 and BDS-3 Broadcast Clock Offsets}

To analyze and evaluate the accuracy of BDS-2 and BDS-3 broadcast clock offsets, we use the algorithm in Section 2.1 to evaluate the broadcast clock offsets. When calculating the error of the broadcast clock offsets, the average BMP clock values of satellites of the same constellation is subtracted to eliminate the datum of the broadcast clock [26]. Selecting the same reference satellite or calculating average BMP clock values of satellites of the same constellation cannot eliminate the datum of the broadcast clock under the condition that the datum of precise clock offsets is unified, which can indirectly prove that the datum of broadcast clock offsets for BDS-2 and BDS-3 are inconsistent. Unfortunately, the average BMP clock values of BDS-2 and BDS-3 are not equal. Figure 4 shows the 
average BMP clock values of BDS-2 and BDS-3 and its differences. Figure 4, we can see that three ACs have different trends in the time series of average BMP clock values, which results from the different reference clocks used by the different ACs. The average BMP clock values of BDS-2 and BDS-3 are not equal, there are differences between BDS-2 and BDS-3, which can indirectly prove that the datum of broadcast clock offsets for BDS-2 and BDS-3 are inconsistent. About the difference between BDS-2 and BDS-3 in time series of average BMP clock values, we can find the multiday stability of GFZ, WHU and SHA are relatively better. From DOY 089 to 123 , the daily average of the differences for GFZ, WHU and SHA are around 15.4 ns, 18.8 ns and 5.8 ns, respectively. Figure 5 depicts the standard deviations (STD) of the differences in average BMP clock values between BDS-2 and BDS-3. The STD of GFZ, WHU and SHA are all better than 1 ns during the whole data test period.

In order to reduce the impact of the inconsistency of the datum of broadcast clock offsets on the assessment of BDS-2 and BDS-3 signal-in-space accuracy and SPP, Zhang and Wang [12] attribute this bias to satellite-dependent TGD bias of the BDS broadcast ephemeris, and estimate TGD bias to weaken this impact. Even if TGD bias is used to correct this inconsistency, its residuals will still affect signal-in-space accuracy and SPP. To ensure the objectivity and stability of the assessment of signal-in-space accuracy, we regard BDS-2 and BDS-3 as two systems, and solve separately their average BMP clock values of all satellites to get the error of the broadcast clock offset.

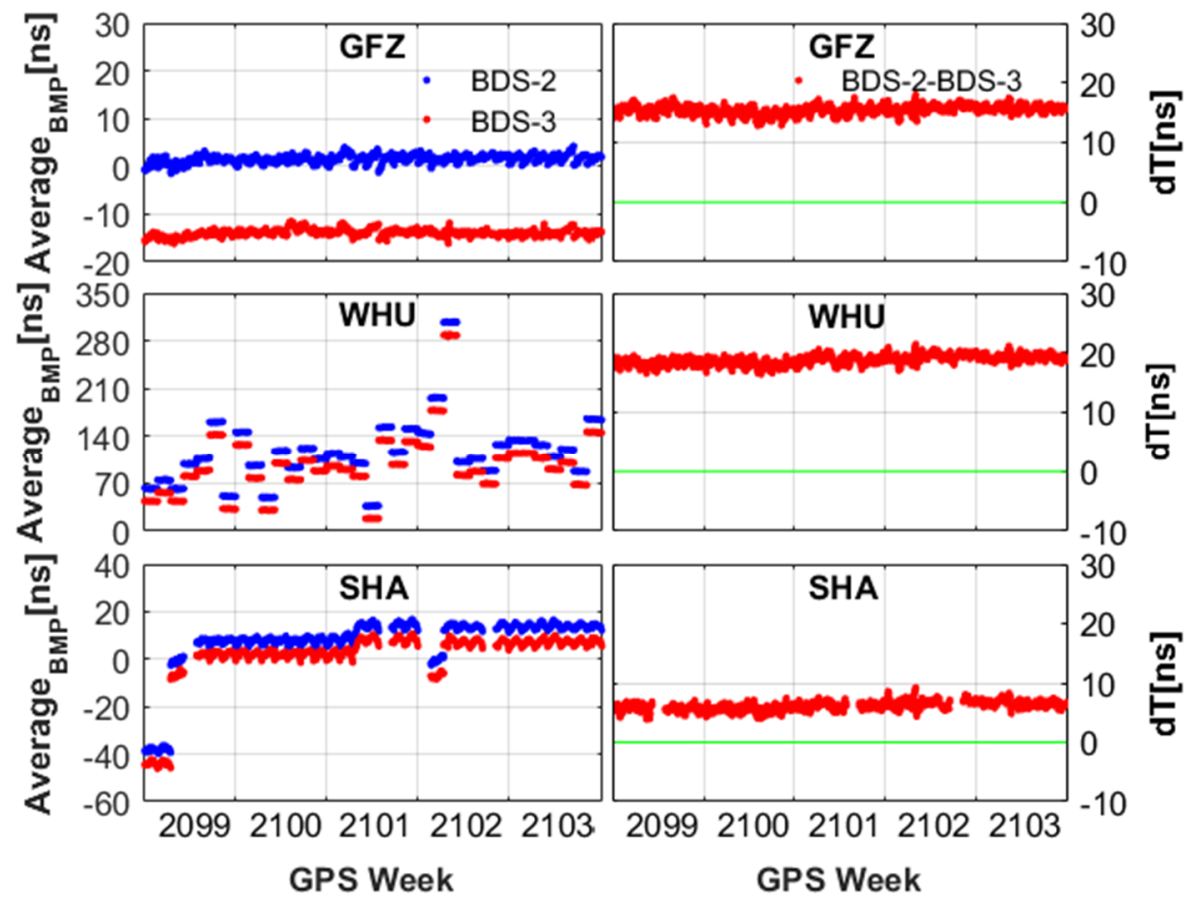

Figure 4. The time series of average broadcast-minus-precise clock values of BDS-2 and BDS-3 and its differences.

Figure 6 depicts the BDS-2 and BDS-3 clock errors for the broadcast clock offsets, in which the precise clock offsets provided by GFZ, WHU and SHA are regarded as the reference values, respectively. From Figure 6, we can get the clock errors of BDS-2 and BDS-3 are better than $10 \mathrm{~ns}$ and 5 ns, respectively. As illustrated in the previous section, the precise products are missing on some days, the corresponding clock errors obtained are also missing. In order to display the accuracy and stability of the broadcast clock offsets of each BDS satellite, this contribution gives the time series of STD and root mean square (RMS) error of BDS clock errors. From the perspective of STD, the STD of BDS clock errors calculated by GFZ, WHU and SHA performs great consistency. From Figure 7, the 35-day STDs of BDS-2 clock errors calculated by GFZ, WHU and SHA are all better than 2 ns, except for a few days. With the upgrade of BDS-3 satellite hardware technology and the development of precise orbit determination 
(POD) algorithms, the 35-day STDs of BDS-3 clock errors are better than $1 \mathrm{~ns}$, except for C45 and C46. The time of C45 and C46 satellites in orbit is very short because they have just been launched. Some GNSS tracking stations cannot receive the observation data of C45 and C46, the available observation data used for POD is limited. Therefore, the accuracy and stability of orbit and clock offsets are slightly worse than other BDS-3 satellites, and the corresponding STD performs worse.

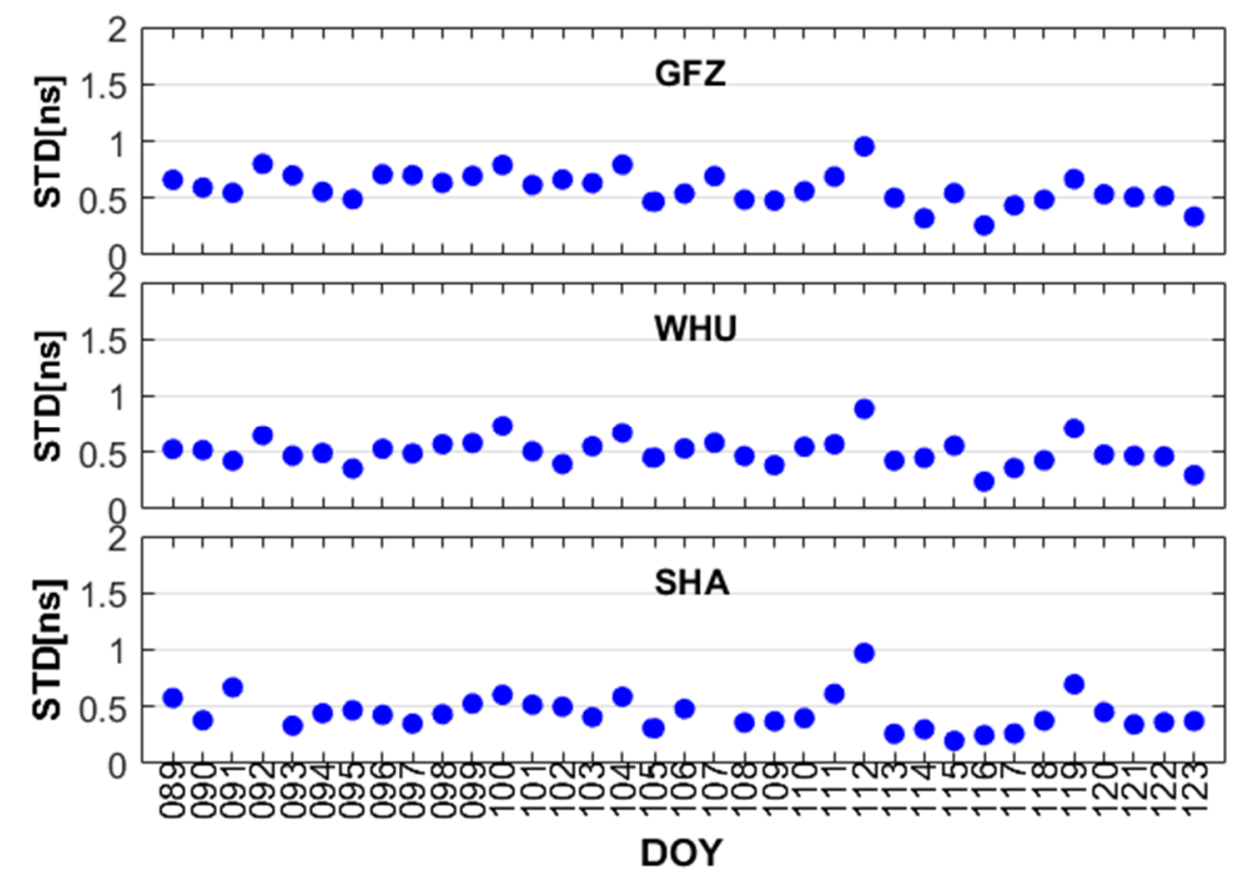

Figure 5. The STD of the average broadcast-minus-precise clock values differences between BDS-2 and BDS-3.
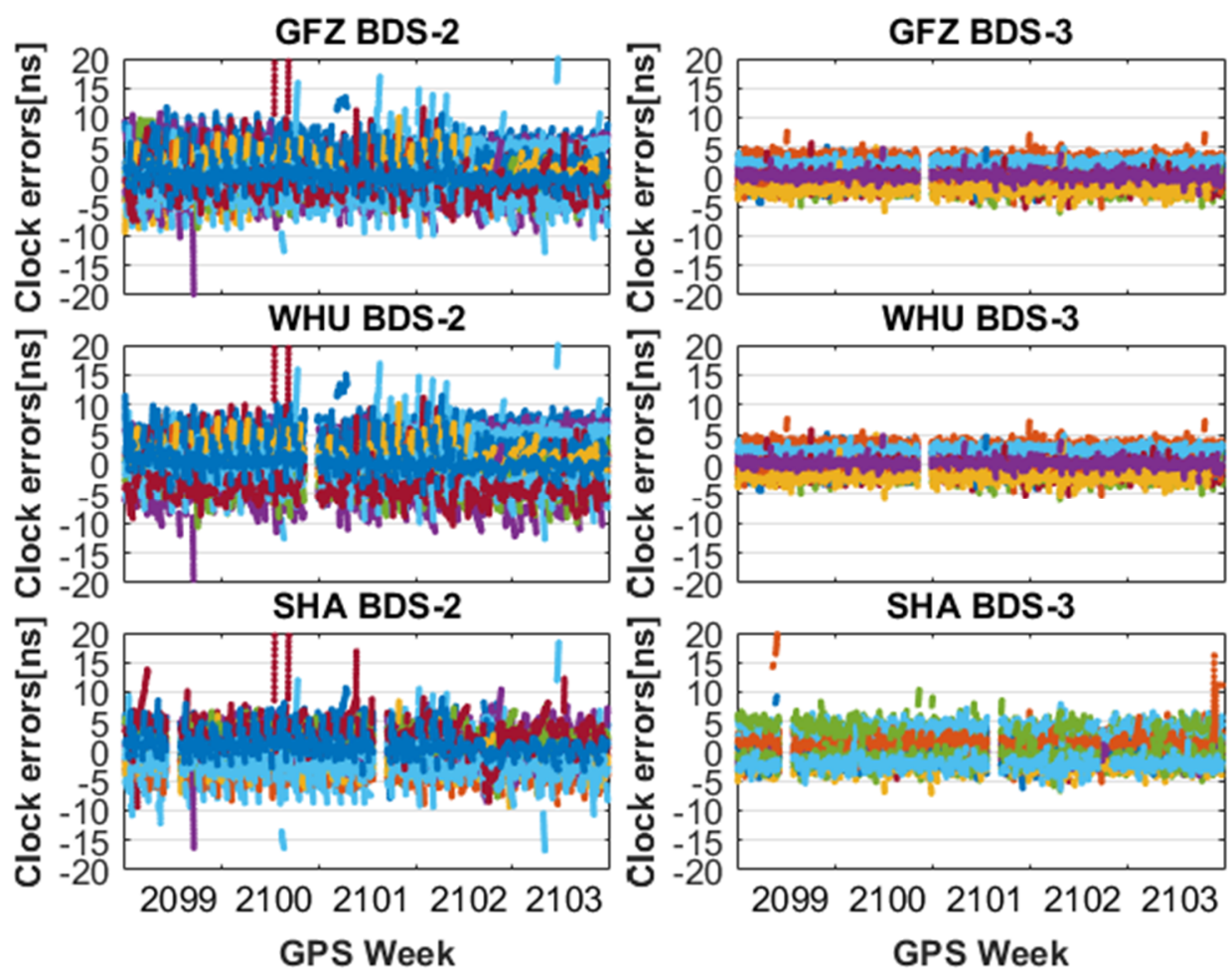

Figure 6. The BDS-2 and BDS-3 clock errors between broadcast clock offsets and the precise clock offsets obtained from GFZ, WHU and SHA. 
Now turn to the RMS of BDS clock errors, which is shown in Figure 8, the BDS-3 has improvement in terms of RMS compared with BDS-2. The RMS of BDS-3 clock errors are better than 3 ns, except for individual satellites. From the perspective of the results obtained by three ACs, the RMS of three ACs performs some difference in C01, C11, C14, C38 and C39 (WHU has not provided the precise products after C37, so there are no assessment results after C37). Although the datum of the satellite clock offsets can be eliminated by double difference, the error of the broadcast clock offset will absorb the new datum of the reference clock. Because the processing strategies of precise clock offsets adopted by different ACs are different, there are also differences in the new datum of the reference clock. Therefore, different ACs have poor RMS consistency but with the great STD consistency. Therefore, it is more scientific and rigorous to assess broadcast ephemeris with precise products solved by different ACs.

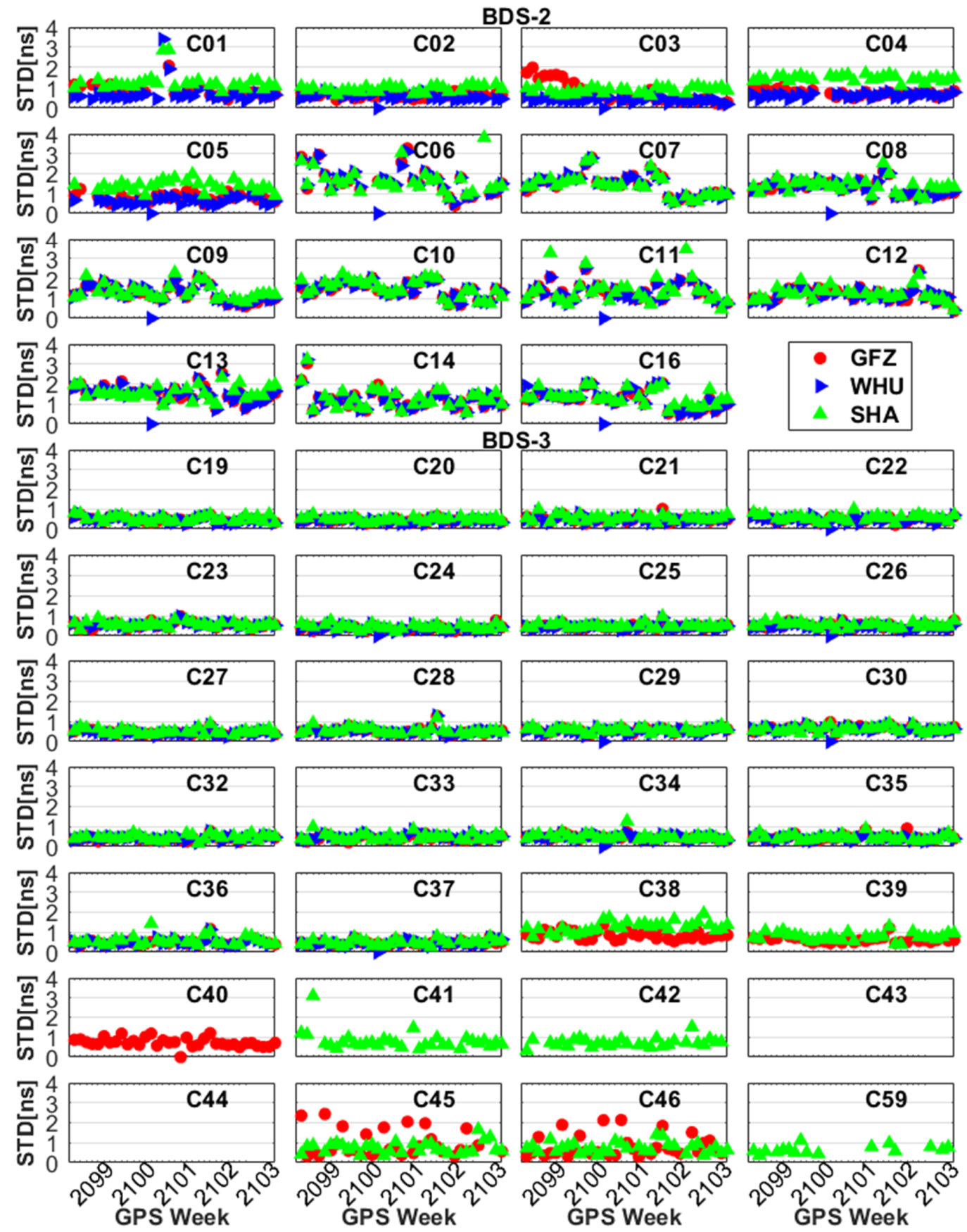

Figure 7. The STD time series of BDS clock errors between broadcast clock offsets and the precise clock offsets obtained from GFZ, WHU and SHA. 


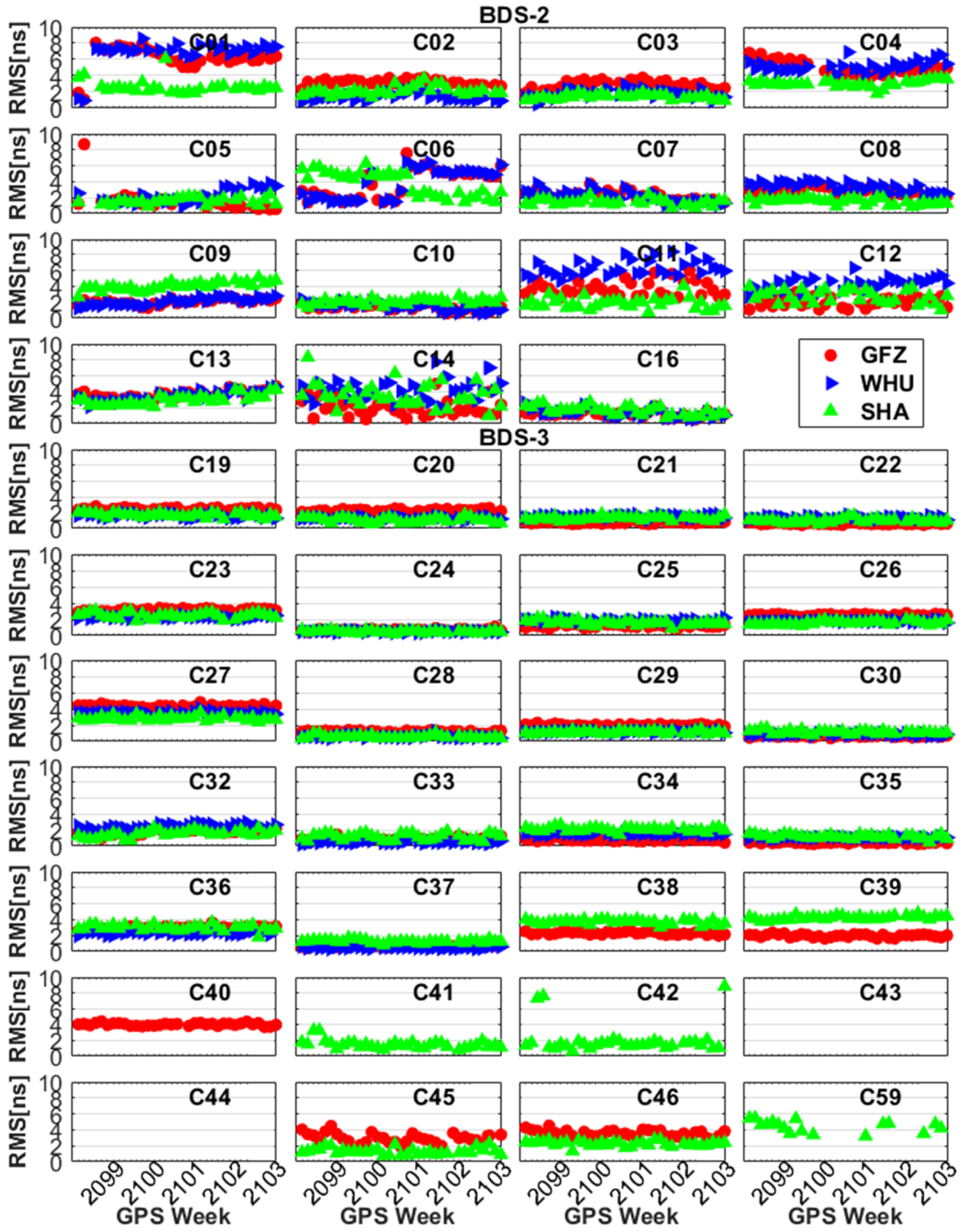

Figure 8. The RMS time series of BDS clock errors between broadcast clock offsets and the precise clock offsets obtained from GFZ, WHU and SHA.

In order to show the accuracy of BDS broadcast clock offsets more intuitively, Table 4 illustrates the mean STD and RMS statistics of broadcast clock errors for each BDS satellite. The STD of all BDS-2 satellites is better than $2.00 \mathrm{~ns}$ for three ACs. With the development of BDS, the STD of BDS-3 satellites is approximately better than $0.77 \mathrm{~ns}$ for three ACs. The mean STD of all BDS-2 satellites for GFZ, WHU and SHA are $1.22 \mathrm{~ns}, 1.18 \mathrm{~ns}$ and $1.34 \mathrm{~ns}$, and the mean STD of all BDS-3 satellites for three ACs are $0.55 \mathrm{~ns}, 0.59 \mathrm{~ns}$ and $0.47 \mathrm{~ns}$, respectively. The improvement rate of BDS-3 STD of GFZ, WHU and SHA are $54.65 \%, 60.18 \%$ and $56.14 \%$ compared to BDS-2, respectively. The mean STD of all BDS-2 satellites of three ACs is $1.22 \mathrm{~ns}$, and BDS-3 is $0.58 \mathrm{~ns}$. The improvement rate of BDS-3 mean STD is $52.49 \%$ compared to BDS-2.

About the RMS statistics of broadcast clock errors, as mentioned earlier in this paper, the broadcast clock error will absorb the new datum of the reference clock. Hence, the inconsistencies of the broadcast clock errors exist for the same satellite in different ACs. The mean RMS of all BDS-2 satellites for GFZ, WHU and SHA are $2.92 \mathrm{~ns}, 3.32 \mathrm{~ns}$ and $2.45 \mathrm{~ns}$, and that of BDS-3 for three ACs are $1.90 \mathrm{~ns}, 1.46 \mathrm{~ns}$ and $1.84 \mathrm{~ns}$, respectively. RMS of BDS-3 broadcast clock errors for the GFZ, WHU and SHA can improve $34.66 \%, 55.84 \%$ and $24.51 \%$ compared to that of BDS-2, respectively. The mean RMS of all BDS-2 and 
BDS-3 satellites of three ACs are $2.90 \mathrm{~ns}$ and $1.73 \mathrm{~ns}$, respectively, and that of BDS-3 can improve $40.34 \%$ compared to BDS-2. From the perspective of comprehensive statistical results, there is a small difference between GFZ, WHU and SHA in STD statistical results and improvement rate. However, the RMS statistical results and improvement rate for GFZ, WHU and SHA are slightly different in some BDS satellites. These findings and conclusions are consistent with Figures 7 and 8.

Table 4. Statistics of the mean STD and RMS of broadcast clock errors for BDS satellites from DOY 089 to 123,2020

\begin{tabular}{|c|c|c|c|c|c|c|c|c|}
\hline \multirow{2}{*}{ PRN } & \multicolumn{2}{|c|}{ GFZ } & \multicolumn{2}{|c|}{ WHU } & \multicolumn{2}{|c|}{ SHA } & \multicolumn{2}{|c|}{ Mean } \\
\hline & STD & RMS & STD & RMS & STD & RMS & STD & RMS \\
\hline $\mathrm{C} 01$ & $0.94 \mathrm{~ns}$ & $6.29 \mathrm{~ns}$ & $0.73 \mathrm{~ns}$ & $6.87 \mathrm{~ns}$ & $1.24 \mathrm{~ns}$ & $2.76 \mathrm{~ns}$ & $0.94 \mathrm{~ns}$ & $5.31 \mathrm{~ns}$ \\
\hline $\mathrm{C} 02$ & $0.72 \mathrm{~ns}$ & $3.17 \mathrm{~ns}$ & $0.78 \mathrm{~ns}$ & $1.39 \mathrm{~ns}$ & $0.94 \mathrm{~ns}$ & $2.09 \mathrm{~ns}$ & $0.71 \mathrm{~ns}$ & $2.22 \mathrm{~ns}$ \\
\hline $\mathrm{C} 03$ & $0.87 \mathrm{~ns}$ & $2.88 \mathrm{~ns}$ & $0.71 \mathrm{~ns}$ & $1.77 \mathrm{~ns}$ & $0.87 \mathrm{~ns}$ & $1.41 \mathrm{~ns}$ & $0.69 \mathrm{~ns}$ & $2.02 \mathrm{~ns}$ \\
\hline C04 & $0.85 \mathrm{~ns}$ & $4.94 \mathrm{~ns}$ & $0.64 \mathrm{~ns}$ & $5.16 \mathrm{~ns}$ & $1.45 \mathrm{~ns}$ & $3.10 \mathrm{~ns}$ & $0.95 \mathrm{~ns}$ & $4.40 \mathrm{~ns}$ \\
\hline C05 & $0.97 \mathrm{~ns}$ & $1.62 \mathrm{~ns}$ & $0.84 \mathrm{~ns}$ & $2.20 \mathrm{~ns}$ & $1.36 \mathrm{~ns}$ & $1.62 \mathrm{~ns}$ & $0.92 \mathrm{~ns}$ & $1.81 \mathrm{~ns}$ \\
\hline $\mathrm{C} 06$ & $1.98 \mathrm{~ns}$ & $3.75 \mathrm{~ns}$ & $2.00 \mathrm{~ns}$ & $3.76 \mathrm{~ns}$ & $1.92 \mathrm{~ns}$ & $3.71 \mathrm{~ns}$ & $1.98 \mathrm{~ns}$ & $3.74 \mathrm{~ns}$ \\
\hline $\mathrm{C} 07$ & $1.46 \mathrm{~ns}$ & $2.26 \mathrm{~ns}$ & $1.45 \mathrm{~ns}$ & $2.14 \mathrm{~ns}$ & $1.39 \mathrm{~ns}$ & $1.42 \mathrm{~ns}$ & $1.43 \mathrm{~ns}$ & $1.94 \mathrm{~ns}$ \\
\hline $\mathrm{C} 08$ & $1.30 \mathrm{~ns}$ & $2.84 \mathrm{~ns}$ & $1.31 \mathrm{~ns}$ & $3.33 \mathrm{~ns}$ & $1.37 \mathrm{~ns}$ & $1.54 \mathrm{~ns}$ & $1.32 \mathrm{~ns}$ & $2.57 \mathrm{~ns}$ \\
\hline C09 & $1.26 \mathrm{~ns}$ & $2.09 \mathrm{~ns}$ & $1.29 \mathrm{~ns}$ & $2.10 \mathrm{~ns}$ & $1.32 \mathrm{~ns}$ & $4.01 \mathrm{~ns}$ & $1.29 \mathrm{~ns}$ & $2.73 \mathrm{~ns}$ \\
\hline C10 & $1.46 \mathrm{~ns}$ & $1.35 \mathrm{~ns}$ & $1.46 \mathrm{~ns}$ & $1.48 \mathrm{~ns}$ & $1.51 \mathrm{~ns}$ & $2.09 \mathrm{~ns}$ & $1.47 \mathrm{~ns}$ & $1.64 \mathrm{~ns}$ \\
\hline C11 & $1.39 \mathrm{~ns}$ & $3.75 \mathrm{~ns}$ & $1.38 \mathrm{~ns}$ & $6.35 \mathrm{~ns}$ & $1.44 \mathrm{~ns}$ & $2.01 \mathrm{~ns}$ & $1.40 \mathrm{~ns}$ & $4.04 \mathrm{~ns}$ \\
\hline C12 & $1.20 \mathrm{~ns}$ & $2.07 \mathrm{~ns}$ & $1.17 \mathrm{~ns}$ & $4.30 \mathrm{~ns}$ & $1.23 \mathrm{~ns}$ & $2.76 \mathrm{~ns}$ & $1.20 \mathrm{~ns}$ & $3.04 \mathrm{~ns}$ \\
\hline $\mathrm{C} 13$ & $1.53 \mathrm{~ns}$ & $3.64 \mathrm{~ns}$ & $1.53 \mathrm{~ns}$ & $3.46 \mathrm{~ns}$ & $1.56 \mathrm{~ns}$ & $3.05 \mathrm{~ns}$ & $1.54 \mathrm{~ns}$ & $3.38 \mathrm{~ns}$ \\
\hline C14 & $1.22 \mathrm{~ns}$ & $2.01 \mathrm{~ns}$ & $1.20 \mathrm{~ns}$ & $4.24 \mathrm{~ns}$ & $1.27 \mathrm{~ns}$ & $3.61 \mathrm{~ns}$ & $1.23 \mathrm{~ns}$ & $3.28 \mathrm{~ns}$ \\
\hline C16 & $1.25 \mathrm{~ns}$ & $1.18 \mathrm{~ns}$ & $1.29 \mathrm{~ns}$ & $1.31 \mathrm{~ns}$ & $1.32 \mathrm{~ns}$ & $1.54 \mathrm{~ns}$ & $1.29 \mathrm{~ns}$ & $1.34 \mathrm{~ns}$ \\
\hline C19 & $0.48 \mathrm{~ns}$ & $2.42 \mathrm{~ns}$ & $0.45 \mathrm{~ns}$ & $1.58 \mathrm{~ns}$ & $0.51 \mathrm{~ns}$ & $1.67 \mathrm{~ns}$ & $0.48 \mathrm{~ns}$ & $1.89 \mathrm{~ns}$ \\
\hline $\mathrm{C} 20$ & $0.44 \mathrm{~ns}$ & $2.21 \mathrm{~ns}$ & $0.42 \mathrm{~ns}$ & $1.25 \mathrm{~ns}$ & $0.49 \mathrm{~ns}$ & $1.06 \mathrm{~ns}$ & $0.45 \mathrm{~ns}$ & $1.51 \mathrm{~ns}$ \\
\hline $\mathrm{C} 21$ & $0.49 \mathrm{~ns}$ & $0.73 \mathrm{~ns}$ & $0.48 \mathrm{~ns}$ & $1.51 \mathrm{~ns}$ & $0.56 \mathrm{~ns}$ & $1.29 \mathrm{~ns}$ & $0.51 \mathrm{~ns}$ & $1.18 \mathrm{~ns}$ \\
\hline $\mathrm{C} 22$ & $0.49 \mathrm{~ns}$ & $0.60 \mathrm{~ns}$ & $0.47 \mathrm{~ns}$ & $1.32 \mathrm{~ns}$ & $0.57 \mathrm{~ns}$ & $1.00 \mathrm{~ns}$ & $0.51 \mathrm{~ns}$ & $0.97 \mathrm{~ns}$ \\
\hline $\mathrm{C} 23$ & $0.55 \mathrm{~ns}$ & $3.14 \mathrm{~ns}$ & $0.56 \mathrm{~ns}$ & $2.26 \mathrm{~ns}$ & $0.57 \mathrm{~ns}$ & $2.44 \mathrm{~ns}$ & $0.56 \mathrm{~ns}$ & $2.61 \mathrm{~ns}$ \\
\hline C24 & $0.39 \mathrm{~ns}$ & $0.69 \mathrm{~ns}$ & $0.38 \mathrm{~ns}$ & $0.49 \mathrm{~ns}$ & $0.43 \mathrm{~ns}$ & $0.45 \mathrm{~ns}$ & $0.40 \mathrm{~ns}$ & $0.54 \mathrm{~ns}$ \\
\hline $\mathrm{C} 25$ & $0.47 \mathrm{~ns}$ & $1.18 \mathrm{~ns}$ & $0.45 \mathrm{~ns}$ & $1.87 \mathrm{~ns}$ & $0.50 \mathrm{~ns}$ & $1.57 \mathrm{~ns}$ & $0.47 \mathrm{~ns}$ & $1.54 \mathrm{~ns}$ \\
\hline C26 & $0.51 \mathrm{~ns}$ & $2.51 \mathrm{~ns}$ & $0.46 \mathrm{~ns}$ & $1.77 \mathrm{~ns}$ & $0.54 \mathrm{~ns}$ & $1.59 \mathrm{~ns}$ & $0.50 \mathrm{~ns}$ & $1.96 \mathrm{~ns}$ \\
\hline $\mathrm{C} 27$ & $0.47 \mathrm{~ns}$ & $4.31 \mathrm{~ns}$ & $0.45 \mathrm{~ns}$ & $3.51 \mathrm{~ns}$ & $0.50 \mathrm{~ns}$ & $2.86 \mathrm{~ns}$ & $0.47 \mathrm{~ns}$ & $3.56 \mathrm{~ns}$ \\
\hline C28 & $0.53 \mathrm{~ns}$ & $1.19 \mathrm{~ns}$ & $0.51 \mathrm{~ns}$ & $0.55 \mathrm{~ns}$ & $0.53 \mathrm{~ns}$ & $0.55 \mathrm{~ns}$ & $0.52 \mathrm{~ns}$ & $0.76 \mathrm{~ns}$ \\
\hline C29 & $0.56 \mathrm{~ns}$ & $1.98 \mathrm{~ns}$ & $0.53 \mathrm{~ns}$ & $1.19 \mathrm{~ns}$ & $0.58 \mathrm{~ns}$ & $1.11 \mathrm{~ns}$ & $0.56 \mathrm{~ns}$ & $1.42 \mathrm{~ns}$ \\
\hline C30 & $0.65 \mathrm{~ns}$ & $0.64 \mathrm{~ns}$ & $0.62 \mathrm{~ns}$ & $0.84 \mathrm{~ns}$ & $0.61 \mathrm{~ns}$ & $1.13 \mathrm{~ns}$ & $0.63 \mathrm{~ns}$ & $0.87 \mathrm{~ns}$ \\
\hline C32 & $0.41 \mathrm{~ns}$ & $1.71 \mathrm{~ns}$ & $0.43 \mathrm{~ns}$ & $2.47 \mathrm{~ns}$ & $0.46 \mathrm{~ns}$ & $1.59 \mathrm{~ns}$ & $0.43 \mathrm{~ns}$ & $1.92 \mathrm{~ns}$ \\
\hline C33 & $0.44 \mathrm{~ns}$ & $0.97 \mathrm{~ns}$ & $0.47 \mathrm{~ns}$ & $0.47 \mathrm{~ns}$ & $0.47 \mathrm{~ns}$ & $1.13 \mathrm{~ns}$ & $0.46 \mathrm{~ns}$ & $0.86 \mathrm{~ns}$ \\
\hline C34 & $0.47 \mathrm{~ns}$ & $0.76 \mathrm{~ns}$ & $0.46 \mathrm{~ns}$ & $1.52 \mathrm{~ns}$ & $0.50 \mathrm{~ns}$ & $2.08 \mathrm{~ns}$ & $0.48 \mathrm{~ns}$ & $1.45 \mathrm{~ns}$ \\
\hline C35 & $0.45 \mathrm{~ns}$ & $0.42 \mathrm{~ns}$ & $0.42 \mathrm{~ns}$ & $1.06 \mathrm{~ns}$ & $0.45 \mathrm{~ns}$ & $1.19 \mathrm{~ns}$ & $0.44 \mathrm{~ns}$ & $0.89 \mathrm{~ns}$ \\
\hline C36 & $0.51 \mathrm{~ns}$ & $3.02 \mathrm{~ns}$ & $0.50 \mathrm{~ns}$ & $2.31 \mathrm{~ns}$ & $0.57 \mathrm{~ns}$ & $2.95 \mathrm{~ns}$ & $0.53 \mathrm{~ns}$ & $2.76 \mathrm{~ns}$ \\
\hline C37 & $0.46 \mathrm{~ns}$ & $0.71 \mathrm{~ns}$ & $0.45 \mathrm{~ns}$ & $0.45 \mathrm{~ns}$ & $0.49 \mathrm{~ns}$ & $1.25 \mathrm{~ns}$ & $0.47 \mathrm{~ns}$ & $0.81 \mathrm{~ns}$ \\
\hline C38 & $0.86 \mathrm{~ns}$ & $2.31 \mathrm{~ns}$ & - & - & $0.86 \mathrm{~ns}$ & $3.73 \mathrm{~ns}$ & $0.86 \mathrm{~ns}$ & $3.02 \mathrm{~ns}$ \\
\hline C39 & $0.64 \mathrm{~ns}$ & $1.97 \mathrm{~ns}$ & - & - & $0.77 \mathrm{~ns}$ & $4.25 \mathrm{~ns}$ & $0.70 \mathrm{~ns}$ & $3.11 \mathrm{~ns}$ \\
\hline $\mathrm{C} 40$ & $0.76 \mathrm{~ns}$ & $3.99 \mathrm{~ns}$ & - & - & - & - & $0.76 \mathrm{~ns}$ & $3.99 \mathrm{~ns}$ \\
\hline C41 & - & - & - & - & $0.81 \mathrm{~ns}$ & $1.42 \mathrm{~ns}$ & $0.81 \mathrm{~ns}$ & $1.42 \mathrm{~ns}$ \\
\hline $\mathrm{C} 42$ & - & - & - & - & $0.83 \mathrm{~ns}$ & $1.88 \mathrm{~ns}$ & $0.83 \mathrm{~ns}$ & $1.88 \mathrm{~ns}$ \\
\hline $\mathrm{C} 43$ & 一 & - & - & - & - & - & - & - \\
\hline $\mathrm{C} 44$ & - & - & - & - & - & - & - & - \\
\hline C45 & $0.94 \mathrm{~ns}$ & $2.92 \mathrm{~ns}$ & - & - & $0.75 \mathrm{~ns}$ & $1.32 \mathrm{~ns}$ & $0.84 \mathrm{~ns}$ & $2.12 \mathrm{~ns}$ \\
\hline $\mathrm{C} 46$ & $0.84 \mathrm{~ns}$ & $3.54 \mathrm{~ns}$ & - & - & $0.76 \mathrm{~ns}$ & $2.28 \mathrm{~ns}$ & $0.80 \mathrm{~ns}$ & $2.91 \mathrm{~ns}$ \\
\hline C59 & - & - & - & - & $0.65 \mathrm{~ns}$ & $4.41 \mathrm{~ns}$ & $0.65 \mathrm{~ns}$ & $4.41 \mathrm{~ns}$ \\
\hline All BDS-2 & $1.22 \mathrm{~ns}$ & $2.92 \mathrm{~ns}$ & $1.18 \mathrm{~ns}$ & $3.32 \mathrm{~ns}$ & $1.34 \mathrm{~ns}$ & $2.45 \mathrm{~ns}$ & $1.22 \mathrm{~ns}$ & $2.90 \mathrm{~ns}$ \\
\hline All BDS-3 & $0.55 \mathrm{~ns}$ & $1.90 \mathrm{~ns}$ & $0.59 \mathrm{~ns}$ & $1.46 \mathrm{~ns}$ & $0.47 \mathrm{~ns}$ & $1.84 \mathrm{~ns}$ & $0.58 \mathrm{~ns}$ & $1.73 \mathrm{~ns}$ \\
\hline Improvement rate & $54.65 \%$ & $34.66 \%$ & $60.18 \%$ & $55.84 \%$ & $56.14 \%$ & $24.51 \%$ & $52.49 \%$ & $40.34 \%$ \\
\hline
\end{tabular}

Satellites in blue background are part of BDS-2, satellites in green background are part of BDS-3. 


\subsection{BDS-2 and BDS-3 Broadcast Orbit}

Since the reference point of the broadcast orbits is the antenna phase center (APC), and the reference point of the precise orbits is the center of mass (CoM), the orbit errors of precise and broadcast ephemerides can be compared directly after the PCO and PCV corrections [5]. Figure 9 illustrates the orbit errors of BDS-2 and BDS-3 broadcast orbits in radial, along-track and cross-track directions. Since the orbit accuracy of GEO satellites performs poorly, the along-orbit errors of GEO satellites are worse than $10 \mathrm{~m}$ in some time periods. Figure 10 shows the RMS and STD of orbit error of each satellite. Similarly, the orbit accuracy of GEO is obviously worse than that of MEO and IGSO in the along-track direction. Ignoring GEO, the orbit errors of along-track direction are roughly better than $2.8 \mathrm{~m}$ for MEO and IGSO. As BDS second generational satellite navigation systems, ground tracking stations used to calculate broadcast ephemeris are unevenly distributed and the orbit determination strategy is immature, which leads to lower accuracy of the BDS-2 broadcast ephemeris. It is worth noting that the accuracy and stability of BDS-3 orbit have a significant improvement over BDS-2. With the upgrade of BDS-3 satellite hardware technology, especially for inter-satellite links payload and the development of satellite orbit determination algorithm, the orbit accuracy of BDS-3 broadcast orbit has made great progress. As shown in Figures 9 and 10, the orbit errors of BDS-3 is significantly lower than that of BDS-2, and the RMS and STD of three ACs of BDS-3 satellite are better than $0.3 \mathrm{~m}$ and $0.2 \mathrm{~m}$ for radial direction, $0.5 \mathrm{~m}$ and $0.3 \mathrm{~m}$ for the along-track direction, and $0.3 \mathrm{~m}$ and $0.3 \mathrm{~m}$ for the cross-track direction, respectively.

In order to explain the improvement of BDS-3 compared to BDS-2 more objectively and reasonably, Table 5 explains the mean RMS and STD statistical results of BDS-2 and BDS-3 orbit errors and the improvement rate of BDS-3 compared to BDS-2. The consistency of the orbit accuracy between GFZ, WHU, and SHA is relatively excellent. In radial, along-track and cross-track directions, the mean RMS and STD of all BDS-2 satellite are $(1.79,3.28,1.39) \mathrm{m}$ and $(0.32,0.99,1.04) \mathrm{m}$ for GFZ, $(1.78,3.28,1.23)$ $\mathrm{m}$ and $(0.34,1.03,0.98) \mathrm{m}$ for WHU, $(0.81,2.56,1.02) \mathrm{m}$ and $(0.37,0.99,0.95) \mathrm{m}$ for SHA, and $(1.46$, $3.04,1.21) \mathrm{m}$ and $(0.34,1.00,0.99) \mathrm{m}$ for the average of three ACs, respectively. The broadcast orbit accuracy of BDS-3 is roughly improved by one order magnitude compared to BDS-2, the mean RMS and STD of all BDS-3 satellite are $(0.20,0.33,0.29) \mathrm{m}$ and $(0.07,0.25,0.24) \mathrm{m}$ for GFZ, $(0.16,0.30,0.27) \mathrm{m}$ and $(0.05,0.18,0.21) \mathrm{m}$ for WHU, $(0.23,0.35,0.30) \mathrm{m}$ and $(0.09,0.28,0.25) \mathrm{m}$ for SHA, and $(0.20,0.32$, $0.28) \mathrm{m}$ and $(0.07,0.23,0.23) \mathrm{m}$ for the average of three ACs, respectively. The mean RMS and STD of BDS-3 broadcast orbit errors are improved by $(86.30 \%, 89.47 \%, 76.86 \%)$ and $(79.41 \%, 77.00 \%, 76.78 \%)$ compared to BDS-2 in three directions, respectively.

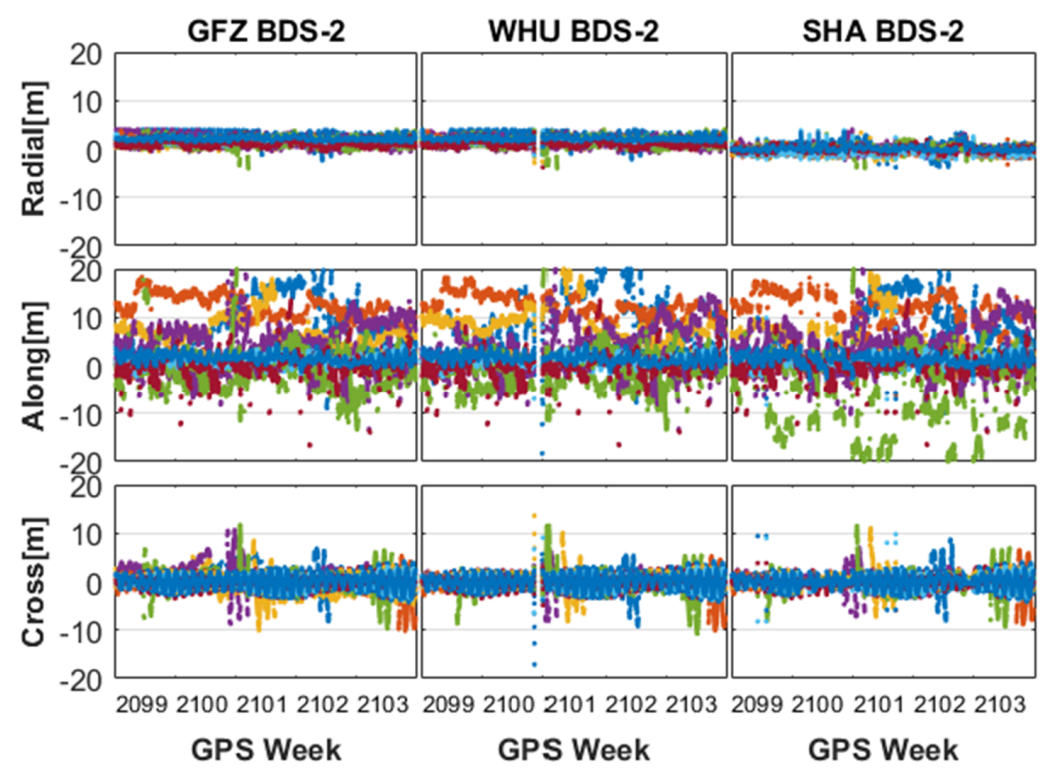

Figure 9. Cont. 


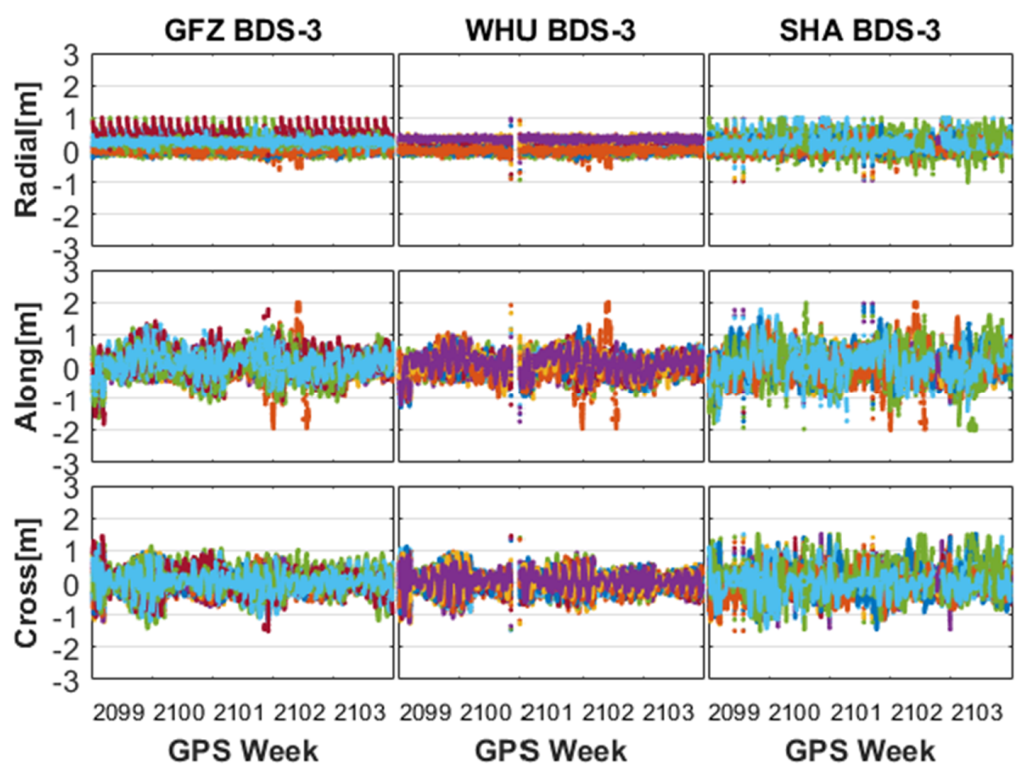

Figure 9. The orbit errors of BDS-2 and BDS-3 broadcast orbits relative to precise ephemerides provided by GFZ, WHU and SHA in radial, along-track and cross-track directions.

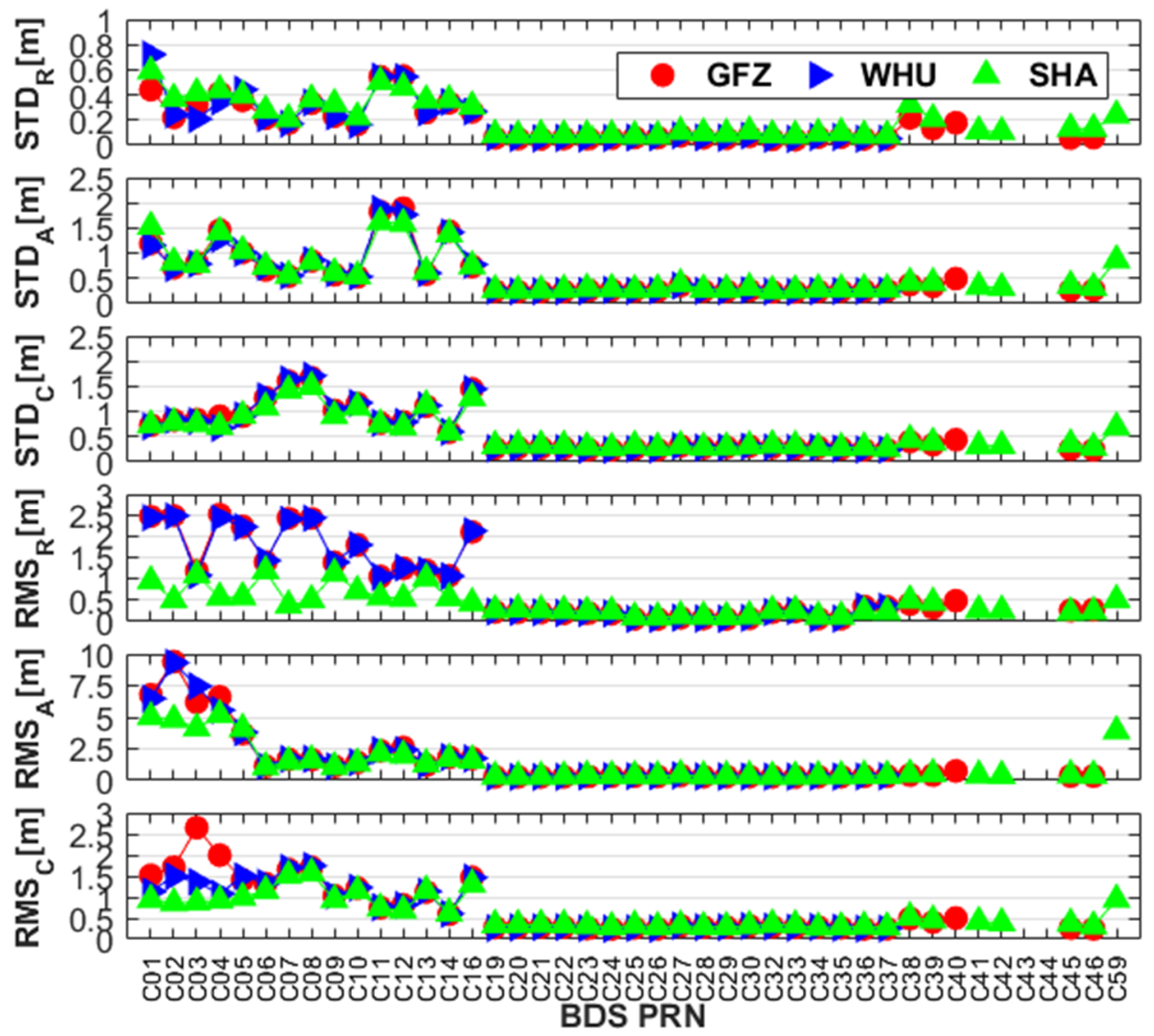

Figure 10. The STD and RMS orbit errors of BDS-2 and BDS-3 broadcast orbits relative to precise ephemerides provided by GFZ, WHU and SHA in radial, along-track and cross-track directions. 
Table 5. The mean RMS and STD statistical results of BDS-2 and BDS-3 orbit errors and the improvement rate of BDS-3 compared to BDS-2 in terms of RMS and STD (DOY 089-123, 2020).

\begin{tabular}{|c|c|c|c|c|c|}
\hline Agency & Items & Track Direction & BDS-2 & BDS-3 & Improvement Rate \\
\hline \multirow{6}{*}{ GFZ } & \multirow{3}{*}{ RMS } & Radial & $1.79 \mathrm{~m}$ & $0.20 \mathrm{~m}$ & $88.83 \%$ \\
\hline & & Along & $3.28 \mathrm{~m}$ & $0.33 \mathrm{~m}$ & $89.94 \%$ \\
\hline & & Cross & $1.39 \mathrm{~m}$ & $0.29 \mathrm{~m}$ & $79.14 \%$ \\
\hline & \multirow{3}{*}{ STD } & Radial & $0.32 \mathrm{~m}$ & $0.07 \mathrm{~m}$ & $78.13 \%$ \\
\hline & & Along & $0.99 \mathrm{~m}$ & $0.25 \mathrm{~m}$ & $74.75 \%$ \\
\hline & & Cross & $1.04 \mathrm{~m}$ & $0.24 \mathrm{~m}$ & $76.92 \%$ \\
\hline \multirow{6}{*}{ WHU } & \multirow{3}{*}{ RMS } & Radial & $1.78 \mathrm{~m}$ & $0.16 \mathrm{~m}$ & $91.01 \%$ \\
\hline & & Along & $3.28 \mathrm{~m}$ & $0.30 \mathrm{~m}$ & $90.85 \%$ \\
\hline & & Cross & $1.23 \mathrm{~m}$ & $0.27 \mathrm{~m}$ & $78.05 \%$ \\
\hline & \multirow{3}{*}{ STD } & Radial & $0.34 \mathrm{~m}$ & $0.05 \mathrm{~m}$ & $85.29 \%$ \\
\hline & & Along & $1.03 \mathrm{~m}$ & $0.18 \mathrm{~m}$ & $82.52 \%$ \\
\hline & & Cross & $0.98 \mathrm{~m}$ & $0.21 \mathrm{~m}$ & $78.57 \%$ \\
\hline \multirow{6}{*}{ SHA } & \multirow{3}{*}{ RMS } & Radial & $0.81 \mathrm{~m}$ & $0.23 \mathrm{~m}$ & $71.60 \%$ \\
\hline & & Along & $2.56 \mathrm{~m}$ & $0.35 \mathrm{~m}$ & $86.33 \%$ \\
\hline & & Cross & $1.02 \mathrm{~m}$ & $0.30 \mathrm{~m}$ & $70.59 \%$ \\
\hline & \multirow{3}{*}{ STD } & Radial & $0.37 \mathrm{~m}$ & $0.09 \mathrm{~m}$ & $75.68 \%$ \\
\hline & & Along & $0.99 \mathrm{~m}$ & $0.28 \mathrm{~m}$ & $71.72 \%$ \\
\hline & & Cross & $0.95 \mathrm{~m}$ & $0.25 \mathrm{~m}$ & $73.68 \%$ \\
\hline \multirow{6}{*}{ Average } & \multirow{3}{*}{ RMS } & Radial & $1.46 \mathrm{~m}$ & $0.20 \mathrm{~m}$ & $86.30 \%$ \\
\hline & & Along & $3.04 \mathrm{~m}$ & $0.32 \mathrm{~m}$ & $89.47 \%$ \\
\hline & & Cross & $1.21 \mathrm{~m}$ & $0.28 \mathrm{~m}$ & $76.86 \%$ \\
\hline & \multirow{3}{*}{ STD } & Radial & $0.34 \mathrm{~m}$ & $0.07 \mathrm{~m}$ & $79.41 \%$ \\
\hline & & Along & $1.00 \mathrm{~m}$ & $0.23 \mathrm{~m}$ & $77.00 \%$ \\
\hline & & Cross & $0.99 \mathrm{~m}$ & $0.23 \mathrm{~m}$ & $76.78 \%$ \\
\hline
\end{tabular}

\subsection{SISRE and Orbit-Only SISRE}

To comprehensively assess the accuracy of BDS-2 and BDS-3 broadcast ephemeris, the SISRE and orbit-only SISRE between BDS-2 and BDS-3 from three ACs (GFZ, WHU and SHA) are presented and analyzed in this section. Figures 11 and 12 present the SISRE and orbit-only SISRE of BDS-2 and BDS-3 broadcast ephemeris, respectively. In order to show SISRE and orbit-only SISRE more clearly, the SISRE and orbit-only SISRE values are shifted by the same amount $(3 \mathrm{~m})$ to avoid overlapping. From Figures 11 and 12, the consistency of GFZ, WHU and SHA performs better in SISRE and orbit-only SISRE and the three ACs' consistency of BDS-3 is significantly better than that of BDS-2. BDS-2 GEO satellites perform poorly in SISRE and orbit-only SISRE due to its special orbit and the immaturity of orbit determination strategy. As mentioned in Figure 2, the precise products of some BDS-3 satellites are missing for three ACs, the corresponding SISRE and orbit-only SISRE are also missing. Combining Figures 11 and 12, we can find that the BDS-3 is significantly better than BDS-2 in terms of SISRE and orbit-only SISRE. As shown in Figure 13, the STD and RMS of SISRE are better than $0.2 \mathrm{~m}$ and $1.5 \mathrm{~m}$ for all BDS-3 satellites, respectively. However, the variations between each BDS-2 satellite are relatively serious compared with BDS-3. The STD of SISRE ranges from $0.2 \mathrm{~m}$ to $0.6 \mathrm{~m}$, and RMS ranges from $0.8 \mathrm{~m}$ to $3.5 \mathrm{~m}$. In fact, different ACs adopt different POD solution strategies, systematic error will inevitably be absorbed into SISRE and orbit-only SISRE. Table 6 shows the final statistical results of each ACs and the average values of three ACs. For BDS-2 signal-in-space accuracy, the mean RMS and STD of three ACs are $(1.78,0.40) \mathrm{m}$ for SISRE, and $(1.72,0.34) \mathrm{m}$ for orbit-only SISRE, which is consistent with Montenbruck and Steigenberger [5]. About the hot topic BDS-3, the mean RMS and STD of three ACs are $(0.50,0.14) \mathrm{m}$ for SISRE, and $(0.17,0.04) \mathrm{m}$ for orbit-only SISRE, respectively. The orbit-only SISRE accuracy of BDS-3 is roughly improved by one order magnitude compared to BDS-2, which is the same as the corresponding orbit accuracy, respectively. Because the improvement of BDS-3 clock 
accuracy is not as obvious as the orbit, the mean RMS and STD of BDS-3 are improved by $(71.91 \%$, $65.00 \%)$ for SISRE and $(90.12 \%, 88.24 \%)$ for orbit-only SISRE compared to BDS-2, respectively.

.Due to the inconsistency of the datum of broadcast clock offsets between BDS-2 and BDS-3, BDS-2 and BDS-3 cannot solve SISRE together. The SISRE processing strategies of calculating SISRE of BDS-2 and BDS-3 separately achieve or even exceed the SISRE accuracy corrected by TGD bias [12]. Without additional bias correction, the SISRE processing strategies of calculating SISRE of BDS-2 and BDS-3 separately can more scientifically and accurately reflect the accuracy of the current broadcast ephemeris of BDS-2 and BDS-3.

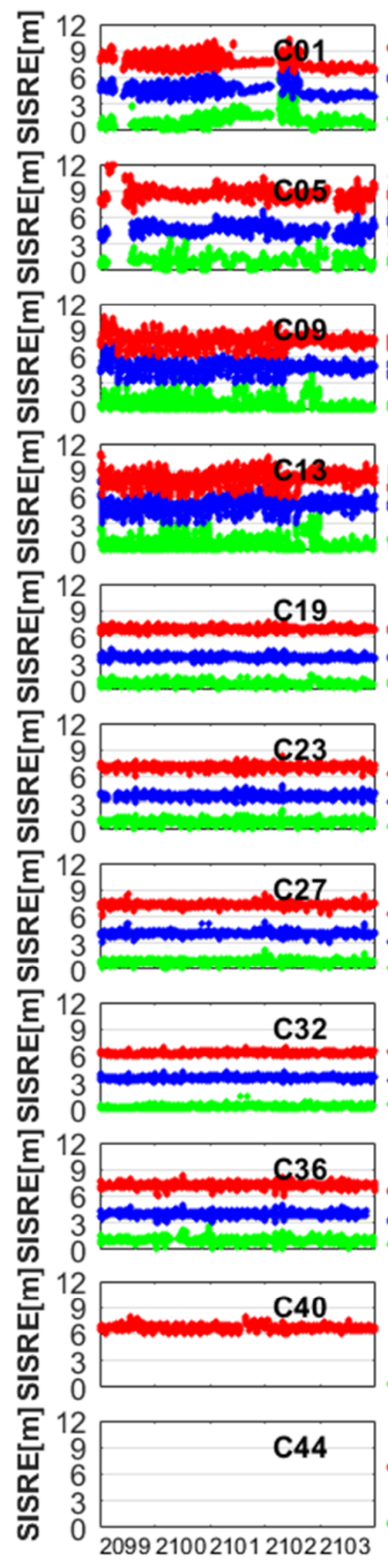

GPS Week
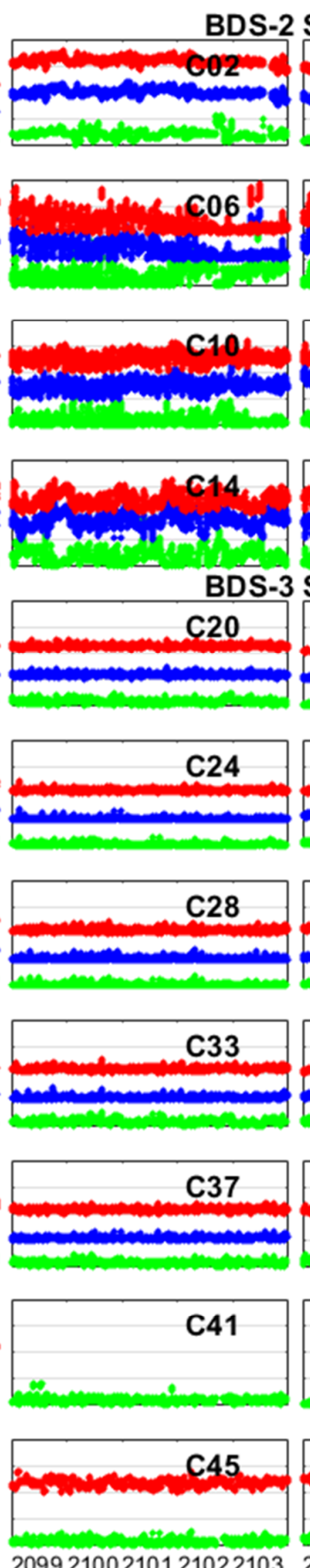

GPS Week
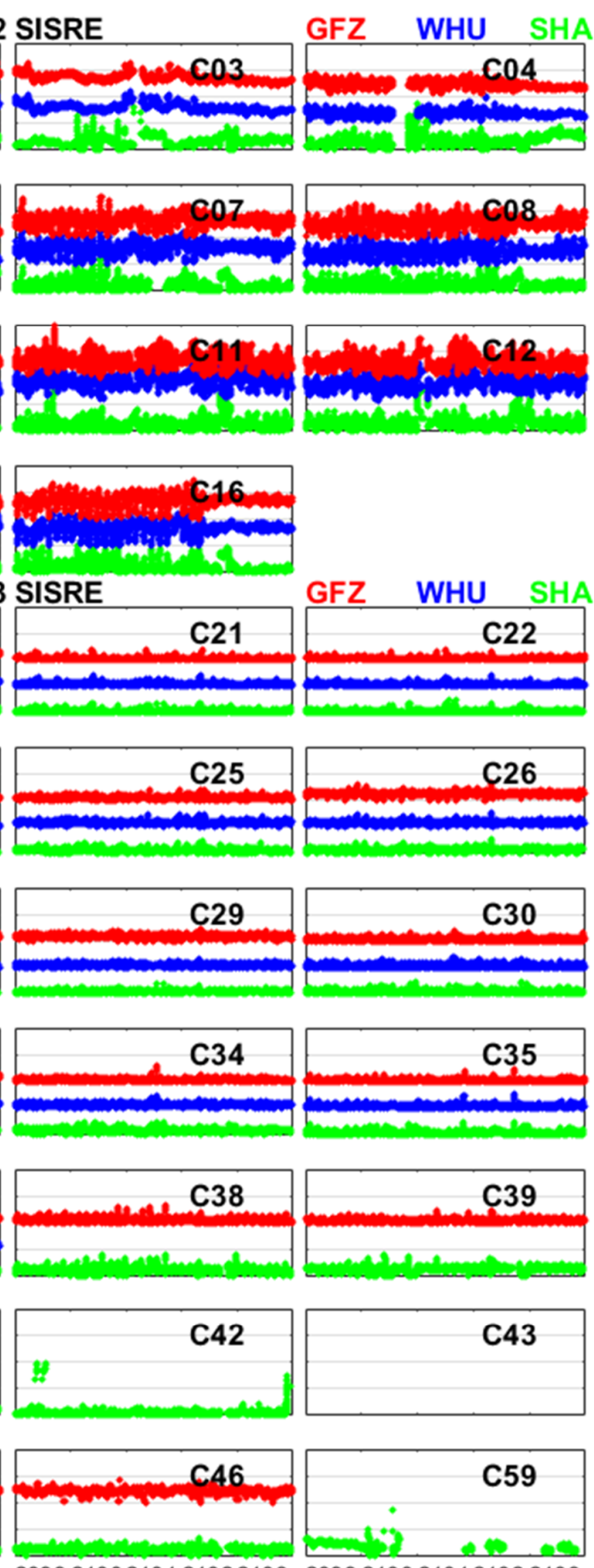

GPS Week

GPS Week

Figure 11. Signal-in-space-range errors of BDS-2 and BDS-3 broadcast ephemeris from DOY 089 to $123,2020$. 


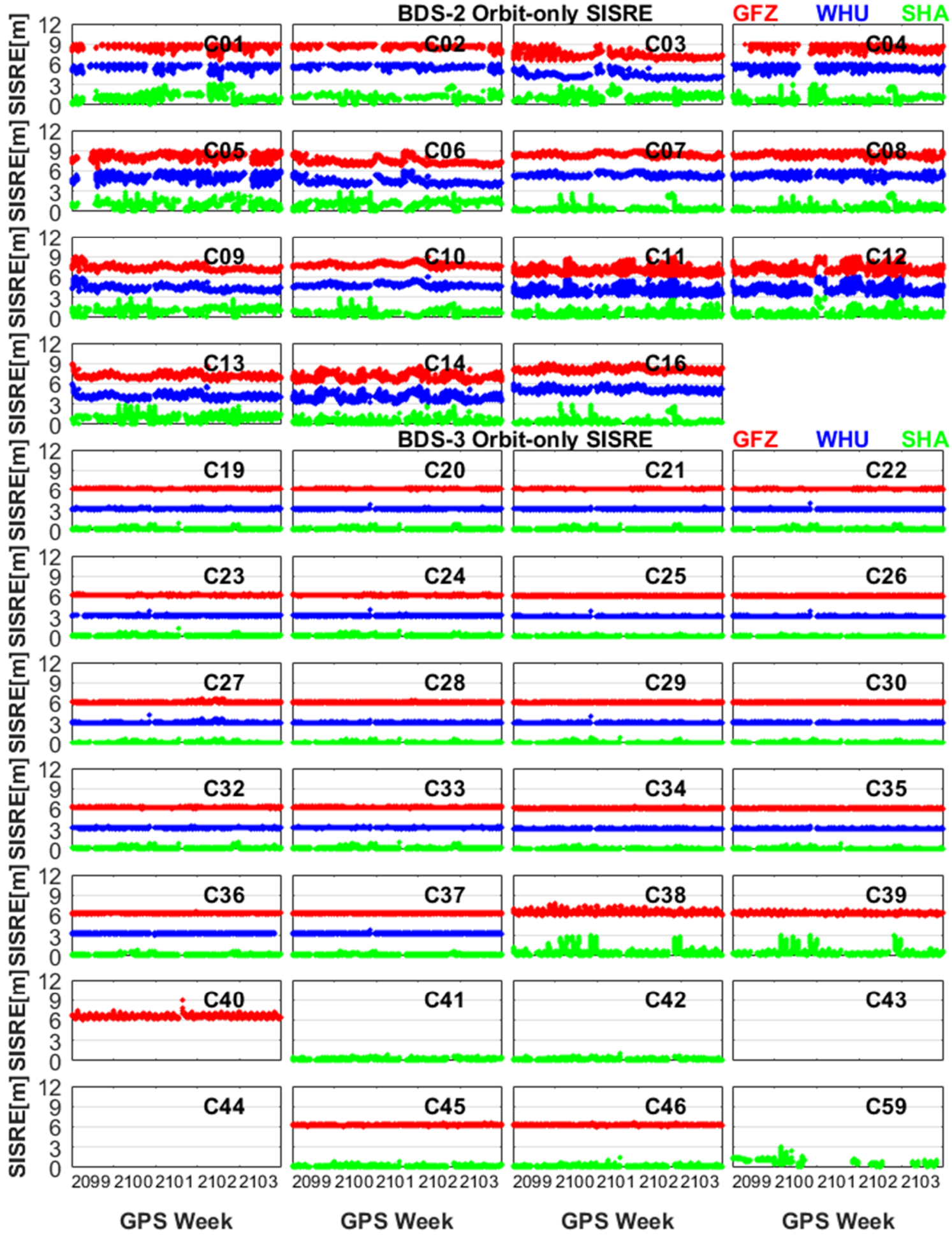

Figure 12. The orbit-only signal-in-space-range errors of BDS-2 and BDS-3 broadcast ephemeris from DOY 089 to 123, 2020. 


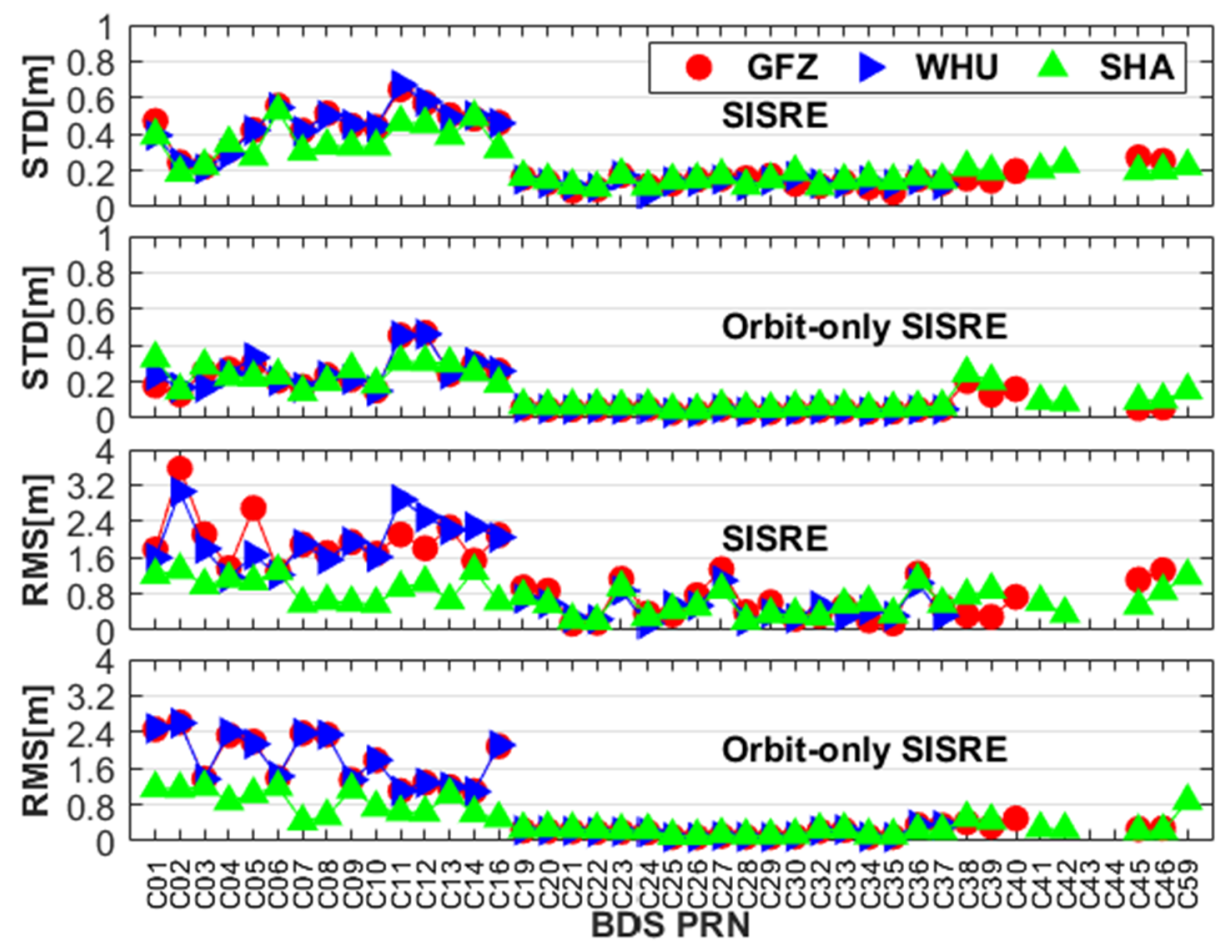

Figure 13. The STD and RMS of SISRE and orbit-only SISRE of broadcast ephemeris relative to precise ephemeris provided by GFZ, WHU and SHA.

Table 6. The mean RMS and STD statistical results of SISRE and orbit-only SISRE and the improvement rate of BDS-3 compared to BDS-2 in terms of RMS and STD (DOY 089-123, 2020).

\begin{tabular}{|c|c|c|c|c|c|}
\hline Agency & & tems & BDS-2 & BDS-3 & Improvement Rate \\
\hline \multirow{4}{*}{ GFZ } & \multirow{2}{*}{ RMS } & SISRE & $2.06 \mathrm{~m}$ & $0.47 \mathrm{~m}$ & $77.18 \%$ \\
\hline & & SISRE & $1.98 \mathrm{~m}$ & $0.16 \mathrm{~m}$ & $91.92 \%$ \\
\hline & \multirow{2}{*}{ STD } & SISRE & $0.41 \mathrm{~m}$ & $0.14 \mathrm{~m}$ & $66.85 \%$ \\
\hline & & SISRE $_{\text {ORBIT }}$ & $0.36 \mathrm{~m}$ & $0.03 \mathrm{~m}$ & $91.67 \%$ \\
\hline \multirow{4}{*}{ WHU } & \multirow{2}{*}{ RMS } & SISRE & $2.02 \mathrm{~m}$ & $0.52 \mathrm{~m}$ & $74.25 \%$ \\
\hline & & SISRE $_{\text {ORBIT }}$ & $1.97 \mathrm{~m}$ & $0.16 \mathrm{~m}$ & $91.88 \%$ \\
\hline & \multirow{2}{*}{ STD } & SISRE & $0.44 \mathrm{~m}$ & $0.14 \mathrm{~m}$ & $68.18 \%$ \\
\hline & & SISRE $_{\text {ORBIT }}$ & $0.34 \mathrm{~m}$ & $0.04 \mathrm{~m}$ & $88.24 \%$ \\
\hline \multirow{4}{*}{ SHA } & \multirow{2}{*}{ RMS } & SISRE & $1.26 \mathrm{~m}$ & $0.52 \mathrm{~m}$ & $58.73 \%$ \\
\hline & & SISRE ORBIT & $1.23 \mathrm{~m}$ & $0.17 \mathrm{~m}$ & $86.18 \%$ \\
\hline & \multirow{2}{*}{ STD } & SISRE & $0.36 \mathrm{~m}$ & $0.14 \mathrm{~m}$ & $61.11 \%$ \\
\hline & & SISRE $_{\text {ORBIT }}$ & $0.36 \mathrm{~m}$ & $0.05 \mathrm{~m}$ & $86.11 \%$ \\
\hline \multirow{4}{*}{ Average } & \multirow{2}{*}{ RMS } & SISRE & $1.78 \mathrm{~m}$ & $0.50 \mathrm{~m}$ & $71.91 \%$ \\
\hline & & SISRE $_{\text {ORBIT }}$ & $1.72 \mathrm{~m}$ & $0.17 \mathrm{~m}$ & $90.12 \%$ \\
\hline & \multirow{2}{*}{ STD } & SISRE & $0.40 \mathrm{~m}$ & $0.14 \mathrm{~m}$ & $65.00 \%$ \\
\hline & & SISRE $_{\text {ORBIT }}$ & $0.34 \mathrm{~m}$ & $0.04 \mathrm{~m}$ & $88.24 \%$ \\
\hline
\end{tabular}

\subsection{The Performance of BDS-2 and BDS-3 Combined SPP}

As mentioned earlier, the datum of broadcast clock offsets for BDS-2 and BDS-3 is inconsistent. From Equations (13) and (14), the ISB contains the inconsistency of the datum of satellite clock offsets and receiver pseudorange bias. In order to research the performance of BDS-2 and BDS-3 combined SPP, the selected observations are divided into seven categories according to the receiver type. According to Equation (13), the selected data is used to calculate the ISB between BDS-2 and BDS-3. Figure 14 
illustrates the 35-day time series of ISB for seven types of receivers. In the seven types of receivers described above, the ISBs of JAVAD TRE_3 are smaller than other receivers, and its average and STD are $-0.75 \mathrm{~m}$ and $0.79 \mathrm{~m}$, respectively.

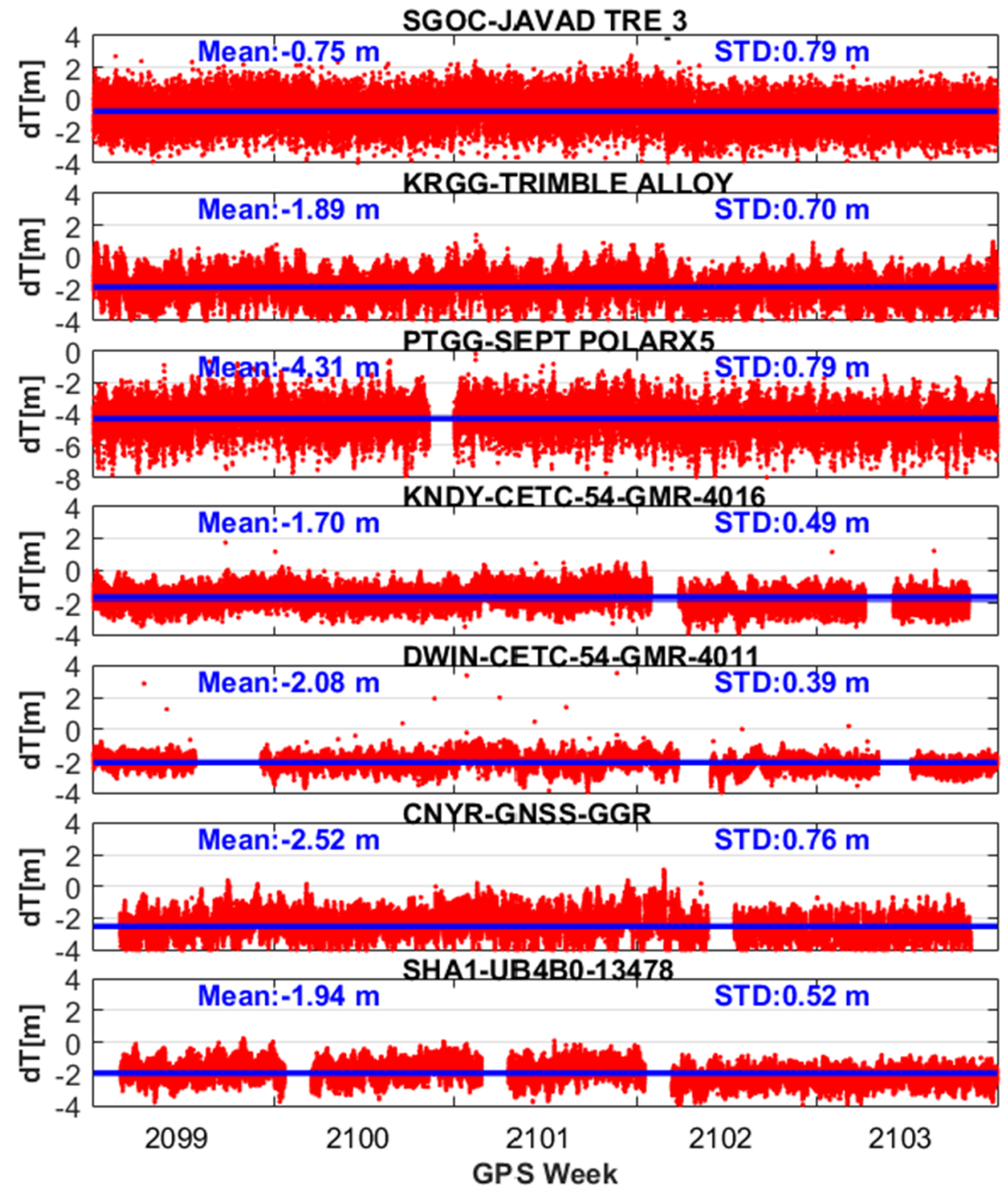

Figure 14. The time series of inter-system bias (ISB) between BDS-2 and BDS-3 for JAVAD TRE_3, TRIMBLE ALLOY, SEPT POLARX5, CETC-54-GMR-4016, CETC-54-GMR-4011, GNSS-GGR and UB4B0-13478 from DOY 089 to 123.

Now turn to the performances of BDS-2 and BDS-3 combined SPP, Figure 15 depicts SPP positioning errors of the selected stations for two different processing cases. Setting ISB parameters to estimate ISB will make the positioning accuracy worse for the tracking stations with JAVAD TRE_3 receiver (POTS, SGOC, ULAB, URUM and WUH2). Combining Figures 14 and 15, we can conclude that when the ISB is relatively minor, setting the parameter to estimate ISB will reduce the stability of the SPP model and make the positioning accuracy of the SPP worse. However, the positioning accuracy of the receivers with relatively large ISB will be improved by setting parameters to estimate ISB. As Table 7 indicates, setting parameters to estimate ISB can improve the positioning accuracy by $20.15 \%, 19.81 \%$ and $12.76 \%$ compared to ordinary BDS SPP models in north, east and up directions, respectively. 


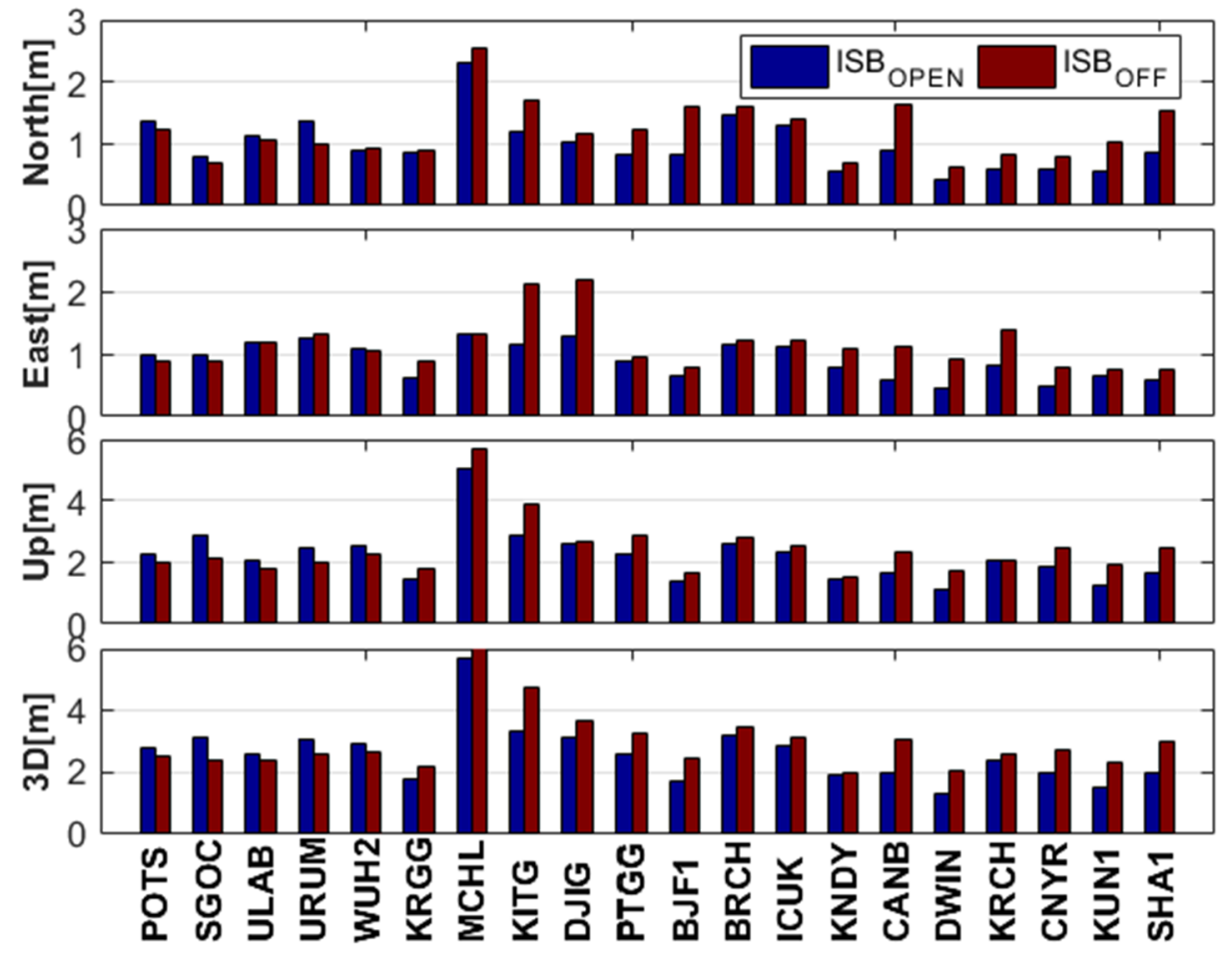

Figure 15. SPP positioning errors of the selected stations for two different processing cases using 35-day observations.

Table 7. Accuracy improvement of BDS-2 and BDS-3 combined SPP with ISB estimation compared to the ordinary BDS SPP model.

\begin{tabular}{cccccc}
\hline Station & Receiver & North & East & Up & 3 D \\
\hline POTS & JAVAD TRE_3 & $-9.71 \%$ & $-9.97 \%$ & $-11.77 \%$ & $-11.00 \%$ \\
SGOC & JAVAD TRE_3 & $-14.90 \%$ & $-11.22 \%$ & $-35.25 \%$ & $-30.61 \%$ \\
ULAB & JAVAD TRE_3 & $-5.37 \%$ & $-1.09 \%$ & $-11.79 \%$ & $-7.93 \%$ \\
URUM & JAVAD TRE_3 & $-40.48 \%$ & $3.20 \%$ & $-24.00 \%$ & $-20.20 \%$ \\
WUH2 & JAVAD TRE_3 & $4.53 \%$ & $-3.00 \%$ & $-13.96 \%$ & $-9.64 \%$ \\
KRGG & TRIMBLE ALLOY & $4.80 \%$ & $31.46 \%$ & $17.44 \%$ & $17.44 \%$ \\
MCHL & TRIMBLE ALLOY & $9.19 \%$ & $0.87 \%$ & $11.38 \%$ & $11.01 \%$ \\
KITG & SEPT POLARX5 & $30.41 \%$ & $45.42 \%$ & $25.91 \%$ & $29.98 \%$ \\
DJIG & SEPT POLARX5 & $12.00 \%$ & $41.38 \%$ & $0.90 \%$ & $14.84 \%$ \\
PTGG & SEPT POLARX5 & $33.59 \%$ & $6.98 \%$ & $20.05 \%$ & $20.65 \%$ \\
BJF1 & CETC-54-GMR-4016 & $49.57 \%$ & $18.71 \%$ & $17.91 \%$ & $29.79 \%$ \\
BRCH & CETC-54-GMR-4016 & $7.86 \%$ & $6.49 \%$ & $8.15 \%$ & $7.92 \%$ \\
ICUK & CETC-54-GMR-4016 & $8.90 \%$ & $9.09 \%$ & $8.85 \%$ & $8.93 \%$ \\
KNDY & CETC-54-GMR-4016 & $20.60 \%$ & $28.69 \%$ & $1.38 \%$ & $3.52 \%$ \\
CANB & CETC-54-GMR-4011 & $44.61 \%$ & $48.29 \%$ & $30.68 \%$ & $36.56 \%$ \\
DWIN & CETC-54-GMR-4011 & $29.55 \%$ & $48.96 \%$ & $33.16 \%$ & $35.82 \%$ \\
KRCH & UNICORE UB4B0I & $29.86 \%$ & $40.29 \%$ & $0.84 \%$ & $7.91 \%$ \\
CNYR & UNICORE UB4B0I & $26.93 \%$ & $37.83 \%$ & $24.70 \%$ & $25.88 \%$ \\
KUN1 & UB4B0-13478 & $46.73 \%$ & $12.34 \%$ & $35.12 \%$ & $34.53 \%$ \\
SHA1 & UB4B0-13478 & $43.84 \%$ & $22.52 \%$ & $32.60 \%$ & $34.68 \%$ \\
\hline & Average 1 & $-13.18 \%$ & $-4.42 \%$ & $-19.36 \%$ & $-15.88 \%$ \\
\hline & Average 2 & $20.15 \%$ & $19.81 \%$ & $12.76 \%$ & $15.49 \%$ \\
\hline
\end{tabular}

Blue background represents BDS-2, Green background represents BDS-3.

\section{Conclusions}

This contribution focused on the analysis and evaluation of BDS-2 and BDS-3 broadcast ephemeris in terms of the accuracy of the orbit and clock offsets, SISRE, orbit-only SISRE and the SPP performances. 
We prove that the datum of broadcast clock offsets for BDS-2 and BDS-3 are inconsistent and propose the SISRE processing strategies of calculating SISRE of BDS-2 and BDS-3 separately and the new BDS-2 and BDS-3 combined SPP model.

From the viewpoint of the assessment of broadcast clock offsets, selecting one and the same average BMP clock values of satellites of the same constellation can eliminate the datum of the satellite clock offsets, and the average BMP clock values of BDS-2 and BDS-3 are not equal, which can indirectly prove that the datum of broadcast clock offsets for BDS-2 and BDS-3 are inconsistent.

To eliminate the datum of the satellite clock offsets and avoid the inconsistency between BDS-2 and BDS-3, the average BMP clock values of BDS-2 and BDS-3 satellites are calculated separately, which can obtain the objective and scientific evaluation results. The mean STD of three ACs for BDS-2 and BDS-3 broadcast clock offsets are $1.22 \mathrm{~ns}$ and $0.58 \mathrm{~ns}$, and the improvement rate of BDS-3 mean STD is $52.49 \%$ compared to BDS-2. Meanwhile, the mean RMS for BDS-2 and BDS-3 are 2.90 ns and 1.73 ns, respectively, and that of BDS-3 can be improved by $40.34 \%$ compared to BDS-2.

About the broadcast orbits, the mean RMS and STD of all BDS-2 satellites are $(1.46,3.04,1.21) \mathrm{m}$ and $(0.34,1.00,0.99) \mathrm{m}$, and that of all BDS-3 satellites are $(0.20,0.32,0.28) \mathrm{m}$ and $(0.07,0.23,0.23) \mathrm{m}$ for the average of three ACs in radial, along-track and cross-track directions, respectively. The broadcast orbit accuracy of BDS-3 is roughly improved by one order magnitude compared to BDS-2. The RMS and STD of BDS-3 broadcast orbit errors are improved by $(86.47 \%, 89.47 \%, 76.86 \%)$ and $(79.41 \%, 77.00 \%$, $76.78 \%$ ) compared to BDS-2 in three directions, respectively.

Due to the inconsistency of the datum of clock offsets for BDS-2 and BDS-3, BDS-2 and BDS-3 cannot solve SISRE together. We propose the SISRE processing strategies of calculating SISRE of BDS-2 and BDS-3 separately. Without additional bias correction, the proposed SISRE processing strategies can more scientifically and accurately reflect the accuracy of the current broadcast ephemeris of BDS-2 and BDS-3. For BDS-2 signal-in-space accuracy, the mean RMS and STD of three ACs are (1.78 and 0.40) $\mathrm{m}$ for SISRE, and (1.72 and 0.34) $\mathrm{m}$ for orbit-only SISRE. As for BDS-3, the mean RMS and STD of three ACs are (0.50 and 0.14) $\mathrm{m}$ for SISRE, and (0.17 and 0.04) $\mathrm{m}$ for orbit-only SISRE, respectively, and the mean RMS and STD of BDS-3 are improved by (71.91\% and $65.00 \%)$ for SISRE and $(90.12 \%$ and $88.24 \%$ ) for orbit-only SISRE compared to BDS-2, respectively. The BDS-3 signal-in-space accuracy has reached $0.50 \mathrm{~m}$, and its accuracy will be further improved with the development of BDS.

In BDS-2 and BDS-3 combined SPP, ISB is affected by the inconsistency of the datum of BDS-2 and BDS-3 broadcast clock offsets and receiver pseudorange bias. Under this background, we analyze the ISB characteristics and SPP performance of different types of receivers separately. For JAVAD TRE_3 receivers, the ISB is relatively minor, and setting the parameter to estimate ISB will reduce the stability of the SPP model and degrade the positioning accuracy of the SPP. However, for the TRIMBLE ALLOY, SEPT POLARX5, CETC-54-GMR-4016, CETC-54-GMR-4011 and UB4B0-13478 receivers, estimating ISB can improve the positioning accuracy by $20.15 \%, 19.81 \%$ and $12.76 \%$ in three directions, respectively.

Finally, we recommend that BDS-2 and BDS-3 should be treated separately when assessing the signal-in-space accuracy of BDS-2 and BDS-3. Furthermore, the performances of BDS-2 and BDS-3 combined SPP can be improved by setting parameters to estimate ISB for receivers with relatively larger ISB values.

Author Contributions: Conceptualization, G.J. and S.S.; methodology, G.J.; software, G.J.; validation, G.J. and Y.L.; formal analysis, G.J.; investigation, G.J. and K.S.; resources, S.S.; data curation, G.J.; writing-original draft preparation, G.J.; writing-review and editing, Y.L., K.S., N.C. and S.W.; visualization, G.J.; supervision, S.S.; project administration, S.S.; funding acquisition, S.S. All authors have read and agreed to the published version of the manuscript.

Funding: This research was funded by the National Key R\&D Program of China, grant number 2016YFB0501503-3 and the key project of National Natural Science Fund, grant number 41730109.

Acknowledgments: The authors gratefully acknowledge GFZ, WHU and SHA for providing BDS-2 and BDS-3 precise orbit and clock products. Many thanks to the IGS MGEX and iGMAS for providing the observation data. Many thanks to iGMAS for funding.

Conflicts of Interest: The authors declare no conflict of interest. 


\section{References}

1. Yang, Y.; Gao, W.; Guo, S.; Mao, Y.; Yang, Y. Introduction to BeiDou-3 navigation satellite system. Navigation 2019, 66, 7-18. [CrossRef]

2. Yang, Y.; Li, J.; Wang, A.; Xu, J.; He, H.; Guo, H.; Shen, J.; Dai, X. Preliminary assessment of the navigation and positioning performance of BeiDou regional navigation satellite system. Sci. China Earth Sci. 2013, 57, 144-152. [CrossRef]

3. Yang, Y.; Li, J.; Xu, J.; Tang, J.; Guo, H.; He, H. Contribution of the Compass satellite navigation system to global PNT users. Chin. Sci. Bull. 2011, 56, 2813-2819. [CrossRef]

4. Yang, Y.; Tang, J.; Montenbruck, O. Chinese navigation satellite systems. In Springer Handbook of Global Navigation Satellite Systems; Teunissen, P.J.G., Montenbruck, O., Eds.; Springer International Publishing: Cham, Switzerland, 2017; pp. 273-304. [CrossRef]

5. Montenbruck, O.; Steigenberger, P.; Hauschild, A. Broadcast versus precise ephemerides: A multi-GNSS perspective. GPS Solut. 2014, 19, 321-333. [CrossRef]

6. Lv, Y.; Geng, T.; Zhao, Q.; Xie, X.; Zhou, R. Initial assessment of BDS-3 preliminary system signal-in-space range error. GPS Solut. 2019, 24. [CrossRef]

7. Zhang, Y.; Kubo, N.; Chen, J.; Wang, J.; Wang, H. Initial positioning assessment of BDS new satellites and new signals. Remote Sens. 2019, 11, 1320. [CrossRef]

8. Jiao, G.; Song, S.; Jiao, W. Improving BDS-2 and BDS-3 joint precise point positioning with time delay bias estimation. Meas. Sci. Technol. 2020, 31. [CrossRef]

9. Dai, P.; Ge, Y.; Qin, W.; Yang, X. BDS-3 time group delay and its effect on standard point positioning. Remote Sens. 2019, 11, 1819. [CrossRef]

10. Wang, N.; Li, Z.; Montenbruck, O.; Tang, C. Quality assessment of GPS, Galileo and BeiDou-2/3 satellite broadcast group delays. Adv. Space Res. 2019, 64, 1764-1779. [CrossRef]

11. Zhang, Y.; Kubo, N.; Chen, J.; Chu, F.-Y.; Wang, A.; Wang, J. Apparent clock and TGD biases between BDS-2 and BDS-3. GPS Solut. 2019, 24. [CrossRef]

12. Zhang, Y.; Wang, H.; Chen, J.; Wang, A.; Meng, L.; Wang, E. Calibration and impact of BeiDou satellite-dependent timing group delay bias. Remote Sens. 2020, 12, 192. [CrossRef]

13. Abdi, N.; Ardalan, A.A.; Karimi, R.; Rezvani, M.-H. Performance assessment of multi-GNSS real-time PPP over Iran. Adv. Space Res. 2017, 59, 2870-2879. [CrossRef]

14. Hong, J.; Tu, R.; Gao, Y.; Zhang, R.; Fan, L.; Zhang, P.; Liu, J. Characteristics of inter-system biases in Multi-GNSS with precise point positioning. Adv. Space Res. 2019, 63, 3777-3794. [CrossRef]

15. Liu, T.; Yuan, Y.; Zhang, B.; Wang, N.; Tan, B.; Chen, Y. Multi-GNSS precise point positioning (MGPPP) using raw observations. J. Geod. 2016, 91, 253-268. [CrossRef]

16. Zhou, F.; Dong, D.; Li, P.; Li, X.; Schuh, H. Influence of stochastic modeling for inter-system biases on multi-GNSS undifferenced and uncombined precise point positioning. GPS Solut. 2019, 23. [CrossRef]

17. CSNO. BeiDou Navigation Satellite System Signal in Space Interface Control Document Open Service Signal (Version 2.1); China Satellite Navigation Office (China): Beijing, China, 2016.

18. CSNO. BeiDou Navigation Satellite System Signal in Space Interface Control Document Open Service Signal B3I (Version 1.0); China Satellite Navigation Office (China): Beijing, China, 2018.

19. CSNO. BeiDou Navigation Satellite System Signal in Space Interface Control Document Open Service Signal B1I (Version 3.0); China Satellite Navigation Office (China): Beijing, China, 2019.

20. Bock, H.; Dach, R.; Jäggi, A.; Beutler, G. High-rate GPS clock corrections from CODE: Support of $1 \mathrm{~Hz}$ applications. J. Geod. 2009, 83, 1083-1094. [CrossRef]

21. Ge, M.; Chen, J.; Douša, J.; Gendt, G.; Wickert, J. A computationally efficient approach for estimating high-rate satellite clock corrections in realtime. GPS Solut. 2011, 16, 9-17. [CrossRef]

22. Tang, C.; Hu, X.; Zhou, S.; Guo, R.; He, F.; Liu, L.; Zhu, L.; Li, X.; Wu, S.; Zhao, G.; et al. Improvement of orbit determination accuracy for Beidou Navigation Satellite System with Two-way Satellite Time Frequency Transfer. Adv. Space Res. 2016, 58, 1390-1400. [CrossRef]

23. Tang, C.; Hu, X.; Zhou, S.; Liu, L.; Pan, J.; Chen, L.; Guo, R.; Zhu, L.; Hu, G.; Li, X.; et al. Initial results of centralized autonomous orbit determination of the new-generation BDS satellites with inter-satellite link measurements. J. Geod. 2018, 92, 1155-1169. [CrossRef] 
24. Montenbruck, O.; Steigenberger, P.; Prange, L.; Deng, Z.; Zhao, Q.; Perosanz, F.; Romero, I.; Noll, C.; Stürze, A.; Weber, G.; et al. The Multi-GNSS Experiment (MGEX) of the International GNSS Service (IGS)_Achievements, prospects and challenges. Adv. Space Res. 2017, 59, 1671-1697. [CrossRef]

25. Kouba, J. A Guide to USING INTERNATIONAL GNSS Service (IGS) Products; Natural Resources: Ottawa, ON, Canada, 2009.

26. Montenbruck, O.; Steigenberger, P.; Hauschild, A. Multi-GNSS signal-in-space range error assessmentMethodology and results. Adv. Space Res. 2018, 61, 3020-3038. [CrossRef]

27. Choi, B.-K.; Cho, C.-H.; Cho, J.H.; Lee, S.J. Multi-GNSS standard point positioning using GPS, GLONASS, BeiDou and QZSS measurements recorded at MKPO reference station in South Korea. J. Position. Navig. Timing 2015, 4, 205-211. [CrossRef]

28. Deng, Z.; Ge, M.; Uhlemann, M.; Zhao, Q. Precise orbit determination of BeiDou satellites at GFZ. In Proceedings of the IGS Workshop, Pasadena, CA, USA, 23-27 June 2014; pp. 23-27.

29. Deng, Z.; Schuh, H. Improvement of multi-GNSS orbit and clock prediction at GFZ. In Proceedings of the EGU General Assembly Conference Abstracts, Vienna, Austria, 8-13 April 2018; p. 2017.

30. Guo, J.; Xu, X.; Zhao, Q.; Liu, J. Precise orbit determination for quad-constellation satellites at Wuhan University: Strategy, result validation, and comparison. J. Geod. 2015, 90, 143-159. [CrossRef]

31. Uhlemann, M.; Gendt, G.; Ramatschi, M.; Deng, Z. GFZ global multi-GNSS network and data processing results. In IAG 150 Years; Springer: Cham, Switzerland, 2015; pp. 673-679.

32. Wang, C.; Zhao, Q.; Guo, J.; Liu, J.; Chen, G. The contribution of intersatellite links to BDS-3 orbit determination: Model refinement and comparisons. Navigation 2019, 66, 71-82. [CrossRef]

33. Liu, T.; Zhang, B.; Yuan, Y.; Li, Z.; Wang, N. Multi-GNSS triple-frequency differential code bias (DCB) determination with precise point positioning (PPP). J. Geod. 2018, 93, 765-784. [CrossRef]

34. Odijk, D.; Teunissen, P.J.G. Characterization of between-receiver GPS-Galileo inter-system biases and their effect on mixed ambiguity resolution. GPS Solut. 2012, 17, 521-533. [CrossRef]

35. Tu, R.; Hong, J.; Zhang, P.; Zhang, R.; Fan, L.; Liu, J.; Lu, X. Multiple GNSS inter-system biases in precise time transfer. Meas. Sci. Technol. 2019, 30. [CrossRef]

36. Dawidowicz, K. Igs08.atx to igs14.atx change dependent differences in a GNSS- derived position time series. Acta Geodyn. Geomater. 2018, 363-378. [CrossRef]

37. Rebischung, P.; Schmid, R. IGS14/igs14.atx: A new framework for the IGS products. In Proceedings of the AGU Fall Meeting, San Francisco, CA, USA, 12-16 December 2016.

38. Landskron, D.; Bohm, J. VMF3/GPT3: Refined discrete and empirical troposphere mapping functions. J. Geod. 2018, 92, 349-360. [CrossRef]

39. Langley, R.B.; Banville, S.; Steigenberger, P. First results: Precise positioning with galileo prototype satellites. GPS World 2012, 23, 45-49.

40. Park, C.; Kim, I.; Lee, J.G.; Jee, G.-I. A satellite selection criterion incorporating the effect of elevation angle in GPS positioning. Control Eng. Pract. 1996, 4, 1741-1746. [CrossRef]

41. Xu, G.; Xu, Y. GPS: Theory, Algorithms and Applications; Springer: Berlin/Heidelberg, Germany, 2016.

42. Petit, G.; Luzum, B. IERS Conventions; No. IERS-TN-36; Bureau International des Poids et Mesures Sevres: Sèvres, France, 2010.

(C) 2020 by the authors. Licensee MDPI, Basel, Switzerland. This article is an open access article distributed under the terms and conditions of the Creative Commons Attribution (CC BY) license (http://creativecommons.org/licenses/by/4.0/). 